OPEN ACCESS

Edited by:

Lorenzo Gerratana,

University of Udine, Italy

Reviewed by:

Reza Ghasemi,

Washington University School of

Medicine in St. Louis, United States

Iman Mamdouh Talaat,

University of Sharjah, United Arab

Emirates

Guohua Zeng,

First Affiliated Hospital of Guangzhou

Medical University, China

*Correspondence:

Gong Cheng

cg0178@qq.com

Xiaoping Zhang

xzhang@hust.edu.cn

${ }^{+}$These authors have contributed equally to this work

Specialty section:

This article was submitted to Cancer Genetics,

a section of the journal

Frontiers in Genetics

Received: 31 December 2020 Accepted: 11 February 2022

Published: 25 February 2022

Citation:

Shou Y, Liu Y, Xu J, Liu J, Xu T, Tong J, Liu L, Hou Y, Liu D, Yang H, Cheng G and Zhang $X$ (2022) TIMP1 Indicates

Poor Prognosis of Renal Cell

Carcinoma and Accelerates

Tumorigenesis via EMT

Signaling Pathway.

Front. Genet. 13:648134.

doi: 10.3389/fgene.2022.648134

\section{TIMP1 Indicates Poor Prognosis of Renal Cell Carcinoma and Accelerates Tumorigenesis via EMT Signaling Pathway}

\author{
Yi Shou ${ }^{1,2 \dagger}$, Yuenan Liu ${ }^{1,2 \dagger}$, Jiaju $X u^{1,2}$, Jingchong Liu ${ }^{1,2}$, Tianbo $X u^{1,2}$, Junwei Tong ${ }^{1,2}$, \\ Lilong Liu $^{1,2}$, Yaxin Hou ${ }^{1,2}$, Di Liu ${ }^{1,2}$, Hongmei Yang ${ }^{1,2}$, Gong Cheng ${ }^{1,2 \star}$ and \\ Xiaoping Zhang ${ }^{1,2 *}$
}

${ }^{1}$ Department of Urology, Union Hospital, Tongji Medical College, Huazhong University of Science and Technology, Wuhan, China, ${ }^{2}$ Institute of Urologic Surgery, Tongji Medical College, Huazhong University of Science and Technology, Wuhan, China,

${ }^{3}$ Department of Pathogenic Biology, School of Basic Medicine, Huazhong University of Science and Technology, Wuhan, China

Renal cell carcinoma (RCC) is one of the most common malignancies in the urinary system. The mortality of advanced RCC remains high despite advances in systemic therapy of RCC. Considering the misdiagnosis of early-stage RCC, the identification of effective biomarkers is of great importance. Tissue inhibitor matrix metalloproteinase 1 (TIMP1), which belongs to TIMP gene family, is a natural inhibitor of the matrix metalloproteinases (MMPs). In this study, we found TIMP1 was significantly up-regulated in cell lines and RCC tissues. Kaplan-Meier analysis revealed that high expression of TIMP1 indicated a poor prognosis. Multivariate analysis further indicated that TIMP1 overexpression was an independent prognostic factor of RCC patients. Furthermore, knockdown of TIMP1 in vitro suppressed the proliferation, migration, and invasion of RCC cells, while upregulating TIMP1 accelerated the proliferation, migration, and invasion of RCC cells. In addition, we also found that TIMP1 prompted the progression of RCC via epithelial-tomesenchymal transition (EMT) signaling pathway. In conclusion, the present results suggested that TIMP1 indicated poor prognosis of renal cell carcinoma and could serve as a potential diagnostic and prognostic biomarker for RCC.

Keywords: TIMP1, renal cell carcinoma (RCC), tumorigenesis, biomarker, EMT-epithelial to mesenchymal transition

\section{INTRODUCTION}

Renal cell carcinoma (RCC) is one of the cancer types that originated from the renal epithelium, which accounts for most cancer-related deaths (Hsieh et al., 2017). The main histological subtypes of RCCs are clear cell (cc) RCC ( $70 \%$ of RCCs), papillary (p) RCC (10\%-15\% of RCCs), and chromophobe (ch) RCC ( $5 \%$ of RCCs) (Morris and Latif, 2017). Cancer-specific survival rates at 5 years for the above three types of RCC are $68.9 \%, 87.4 \%$, and $86.7 \%$, respectively (Cheville et al., 2003; Cinque et al., 2021). The five-year survival rate of early-stage RCC reaches $71 \%-88 \%$. Still, the survival rate at 5 years of RCC plummets to only $12 \%$ when metastasis occurs according to the latest study (Leibovich et al., 2010; Cinque et al., 2021). Therefore, it is necessary to identify practical biomarkers for the early diagnosis of RCC.

Tissue inhibitor matrix metalloproteinase (TIMP) family comprises four paralogous genes (TIMP1, TIMP2, TIMP3, TIMP4) (Brew and Nagase, 2010). TIMPs participate in more 
TABLE 1 | Clinical characteristics of 59 patients with renal cell carcinoma.

\begin{tabular}{|c|c|}
\hline Characteristic & Data \\
\hline Age, mean \pm SEM (years) & $52.3 \pm 13.8$ \\
\hline Gender, male/female & $31 / 28$ \\
\hline Tumor size, mean \pm SEM $(\mathrm{cm})$ & $5.5 \pm 3.1$ \\
\hline Location, right/left & 27/32 \\
\hline \multicolumn{2}{|l|}{ T stage, n (\%) } \\
\hline T1a & $13(22.03)$ \\
\hline $\mathrm{T} 1 \mathrm{~b}$ & $28(47.46)$ \\
\hline $\mathrm{T} 2 \mathrm{a}$ & $8(13.56)$ \\
\hline $\mathrm{T} 2 \mathrm{~b}$ & $5(8.47)$ \\
\hline T3 & $2(3.39)$ \\
\hline T4 & $2(3.39)$ \\
\hline Unknown & $1(1.69)$ \\
\hline \multicolumn{2}{|l|}{ N stage, n (\%) } \\
\hline NO & $54(91.53)$ \\
\hline N1 & $5(8.47)$ \\
\hline \multicolumn{2}{|l|}{ M stage, n (\%) } \\
\hline MO & 56 (94.92) \\
\hline M1 & $3(5.08)$ \\
\hline \multicolumn{2}{|l|}{ Fuhrman grade, $\mathrm{n}(\%)$} \\
\hline 1 & $14(23.73)$ \\
\hline 2 & $27(45.76)$ \\
\hline 3 & $9(15.25)$ \\
\hline 4 & $4(6.78)$ \\
\hline Unknown & $5(8.47)$ \\
\hline
\end{tabular}

protease-independent biological functions including antiapoptosis, anti-angiogenesis, cell cycle regulation, and differentiation activities in epithelial or blood-derived cells (Seo et al., 2003; Cruz-Munoz et al., 2006; Jung et al., 2006; Taube et al., 2006; Grunwald et al., 2019). TIMP1 is a major member of the TIMP family with a molecular weight of $23 \mathrm{KDa}$, which consists of a two-domain structure possessing metalloproteinase-inhibitory and cytokine-like signaling activities (Grunwald et al., 2019). Previous studies showed that high expression of TIMP1 in tissue or blood suggested poor outcomes in various cancers (HoltenAndersen et al., 1999; Wang et al., 2013; Jackson et al., 2017). Song revealed that TIMP1 promoted tumor progression and suppressed apoptosis via FAK-PI3K/AKT and MAPK pathway in colon cancer (Song et al., 2016). Gong found that higher levels of TIMP1 expression were associated with poor prognosis in triple-negative breast cancer (Cheng et al., 2016). Hemmerlein investigated the expression of matrix metalloproteinases and their inhibitors in medulloblastomas and their prognostic relevance (Ozen et al., 2004). In the field of RCC, Kugler's study showed that the balance of MMP-2 and MMP-9 to TIMP-1 and TIMP-2 expression was an essential factor in the aggressiveness of RCC (Kugler et al., 1998). Kallakury pointed out that increased expression of TIMP1 correlated with poor prognostic variables in RCC (Kallakury et al., 2001). Hence, we aimed to explore the relationship between the expression of TIMP1 and clinicopathological factors in renal cancer. Furthermore, we investigated the functional roles of TIMP1 and the underlying biological signal pathway in renal cancer cells.

\section{MATERIALS AND METHODS}

\subsection{RCC Tissue Samples}

A total of 59 pairs of tumor and adjacent normal tissues were obtained from the Department of Urology, Union Hospital, Tongji Medical College (Wuhan, China) between January 2018 and January 2019. The normal kidney tissues were obtained from $2 \mathrm{~cm}$ away from the edge of lesions. The clinical information of these samples was presented in Table 1. The samples were divided into two groups. The first group was immediately stored in liquid nitrogen for RNA and protein extraction. The second group was fixed in formalin and embedded in paraffin, then used for immunohistochemistry assays. Among these samples, we randomly selected 8 pairs of tissues for protein detection, 20 pairs of samples for quantitative real-time PCR and 3 pairs of samples for immunohistochemistry. No patients received anticancer therapy before surgery. All patients gave written informed consent before inclusion in this study, and the study was approved by the Human Research Ethics Committee of Huazhong University of Science and Technology. The study complies with the guidelines of the Declaration of Helsinki.

\subsection{Cell Culture}

The human renal proximal tubular epithelial cell line HK-2, and 5 kinds of human renal cell carcinoma cell lines: 786-O, ACHN, A498, CAKI-1, and OSRC-2, were used in this study and were obtained from the American Type Culture Collection. These cell lines were used for RT-qPCR and western blotting. The cells were grown in Dulbecco's modified Eagles medium containing high glucose $(4.5 \mathrm{~g} / \mathrm{L})$, fetal bovine serum (10\%), and penicillin/ streptomycin solution (1\%). All cells were cultured under standard conditions: at $37^{\circ} \mathrm{C}$ in a $5 \% \mathrm{CO}_{2}$ atmosphere.

\subsection{Immunohistochemical Staining Assays}

The paired RCC tissues and adjacent normal tissues were first fixed in $4 \%$ formalin at room temperature for $12 \mathrm{~h}$, dehydrated, and embedded in paraffin. Then the tissue sections were incubated with rabbit TIMP1 monoclonal antibody (Abcam, ab109125, 1:1,000) overnight at $4^{\circ} \mathrm{C}$. Tissue sections were washed three times with phosphate-buffered saline and incubated with secondary antibodies that were conjugated to horseradish peroxidase at room temperature for $2 \mathrm{~h}$. The sections were scanned by a NanoZoomer S360 (Hamamastu Corporation) and observed with NDP.view2 software (Hamamastu Corporation). Random fields were selected to interpret the expression of TIMP1 in tissue sections under 100x and 400x magnification.

\subsection{RNA Extraction and RT-qPCR}

Total RNA was isolated from tissues or cells using TRIzol ${ }^{\circledR}$ reagent (Thermo Fisher Scientific, Inc.). The concentration and purity of the RNA solution were detected using a NanoDrop 2000 spectrophotometer (NanoDrop Technologies; Thermo Fisher Scientific, Inc.). Total RNA was then reverse transcribed into cDNA using a Superscript II reverse 
transcription kit (Takara Bio, Inc.) according to the manufacturer's protocols. All the experiments were repeated thrice for all the samples. The primers used to amplify TIMP1 and GAPDH were synthesized by TSINGKE Inc. The sequences of forward and reverse primers were as follows: TIMP1-forward: 5'-CGC AGC GAG GAG GTT TCT CAT-3'; TIMP1-reverse: 5' GGC AGT GAT GTG CAA ATT TCC-3'. GAPDH-forward: 5' CGT GGA AGG ACT CAT GAC CA-3'; GAPDH -reverse: $5^{\prime}$ GCC ATC ACG CCA CAG TTT C-3'.

\subsection{Western Blot Assays}

Total protein was extracted from RCC tissues and corresponding adjacent normal tissues of 12 patients using RIPA lysis buffer (Servicbio.Inc.) with protease inhibitor phenyl methane sulfonyl fluoride (PMSF, 1\%), and then the concentration was measured with BCA protein assay kit (Beyotime Biotechnology, Jiangsu, China). Primary rabbit polyclonal antibody against primary antibodies (TIMP1 1:1,000, Abcam,Inc., ab109125; N-cadherin 1:5000, Abcam.Inc., ab76011; E-cadherin 1:10000, Abcam,Inc., ab40772) and $\beta$-actin (1:10000; Abclonal,Inc., cat.AC026) were incubated overnight at $4^{\circ} \mathrm{C}$. All the procedures were performed according to the manufacturer's instructions.

\subsection{Small Interfering RNA and Plasmids Construction, Transfections}

Small interfering RNA (siRNA) oligonucleotide sequences specifically targeting TIMP1 (si-TIMP1) and negative control (siNC) siRNA (cat. no. siBDM 1999A) were obtained from Guangzhou RiboBio Co., Ltd. The plasmids harboring TIMP1 (ov-TIMP1) and negative control (ov-NC) were constructed and supplied by Vigene Biology (Vigene, China). Cells were collected for subsequent experiments $48 \mathrm{~h}$ post transfection. The si-TIMP1 sequence was as follows: 5'-GCC AAT GTG ATG GTG GAC A-3'. The information about the plasmid that has been used for over expression of TIMP1 was provided in Supplementary Figure S1.

\subsection{Cell Proliferation Assay}

One thousand transfected cells were added to each hole in the 96-well plates. Cell proliferation was assessed by the CCK-8 assay (CCK8; Dojindo Molceular Technologies, Inc.) at 24, 48, 72, and $96 \mathrm{~h}$ following treatments, according to the manufacturer's instructions. Ten $\mu \mathrm{l}$ of CCK8 was added to each hole and incubated with cells for $2 \mathrm{~h}$. Then the optical density values were measured by a spectrophotometer at $450 \mathrm{~nm}$ to estimate the number of living cells.

\subsection{Cell Migration and Invasion Assays}

We planted $1 \times 10^{4}$ cells into the upper chambers in serum-free medium for migration and $2 \times 10^{4}$ cells for invasion. Sixty $\mu$ l Matrigel (Thermo Fisher Scientific; Waltham, USA) had been added into the upper chambers for invasion assays. The lower chambers were filled with $600 \mu \mathrm{l}$ DMEM added with 10\% FBS. After $24 \mathrm{~h}$ of incubation, the cells were fixed in $100 \%$ methanol, then stained with $0.05 \%$ crystal violet. Finally, the results were observed under a light microscope at 100x magnification, and the cells passed through the membrane were counted in 3 randomly chosen fields.

\subsection{Bioinformatics Analysis}

TIMP1, TIMP2, TIMP3, and TIMP4 mRNA expression and clinical information of The Cancer Genome Atlas (TCGA) clear cell renal cell carcinoma dataset (TCGA_KIRC) were downloaded from the Xena Functional Genomics Explorer of University of California Santa Cruz (https://xenabrowser.net/). Beroukhim renal, Jones renal, and Yusenko renal datasets (Jones et al., 2005; Beroukhim et al., 2009; Yusenko et al., 2009) were obtained from the Oncomine database (https://www.oncomine. org). The gene set enrichment analysis (GSEA) platform with the Kyoto Encylopedia of Genes and Genomes and Gene Ontology databases (c2.all.v6.2.symbols.gmt) was employed to find pathways enriched in the gene set, based on the pathway Enrichment Score (ES). STRING (Version11.0) was used to explore the protein-protein reaction and biological function of TIMP1(https://string-db.org/).

\subsection{Statistical Analysis}

All statistical analyses were processed by GraphPad Prism 7.0 (GraphPad Software, Inc., USA) and SPSS Statistics 22.0 software (IBM SPSS, Chicago, IL, United States). Data of paired cases were analyzed using a paired student t-test, while analysis of unpaired cases was performed using a one-way analysis of variance (ANOVA) or t-test. Pearson's $\chi 2$ test was applied to analyze the relationship between TIMP1 and TIMP3 expression and clinical parameters. The Kaplan-Meier analysis was used to estimate the correlation between TIMP1 and TIMP3 mRNA expression with overall survival (OS) and disease-free survival (DFS) times with the log-rank test. The TIMP1 mRNA levels downloaded from the TCGA_KIRC dataset were first divided into two groups according to different clinical parameters and then applied to draw receiver operating characteristic (ROC) curves and analyze the area under the curve (AUC) with GraphPad Prism 7.0. The diagnostic value of TIMP1 mRNA expression in RCC was evaluated by ROC curves and AUC. Finally, univariate and multivariate Cox proportional hazard regressions were applied to determine the prognostic significance of TIMP1 and TIMP3. All experiments were repeated thrice independently and all data were represented as mean \pm SEM. A confidence threshold, $p<0.05$, was considered to be statistically significant. ${ }^{*} p<0.05$; ${ }^{* *} p<0.01$; ${ }^{* *} p<$ $0.001 ;{ }^{* * *} p<0.0001$.

\section{RESULTS}

\subsection{TIMP1 Was Upregulated in RCC}

To determine whether TIMP expression was related to the occurrence and progress of RCC, we downloaded the mRNA of 4 members in this family (TIMP1, TIMP2, TIMP3, and TIMP4) from TCGA_KIRC and drew a heatmap of them according to their mRNA expression. The result showed that TIMP1 was upregulated in RCC tissues (Figure 1). It was further verified that TIMP1 was found in higher expression levels in paired comparison (Figure 2A). To confirm these results, we compared the mRNA expression of TIMP1 in Oncomine datasets (Beroukhim, Jones, and Yusenko) and it was shown that TIMP1 was highly expressed in renal cancer samples (Figure 2B). All 


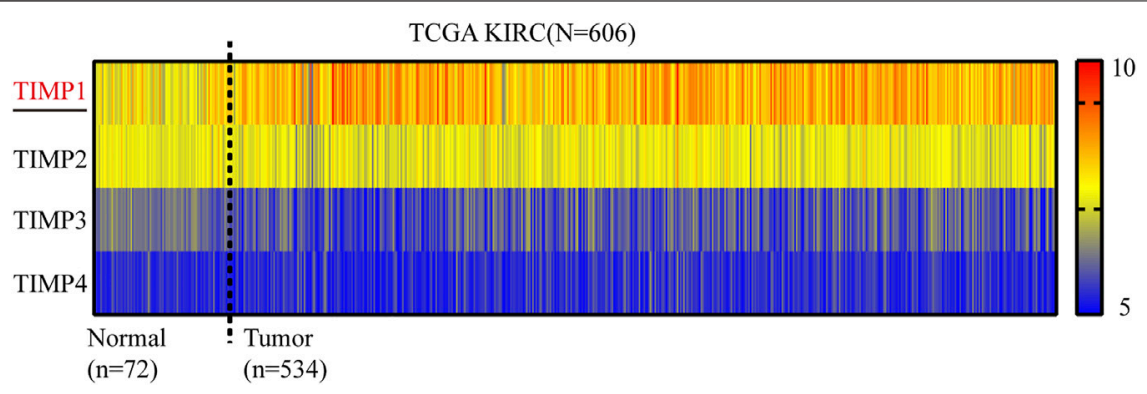

FIGURE 1 | Heatmap of mRNA expression levels of TIMP family obtained from TCGA_KIRC. Red represented high expression and blue represented low expression. TIMP, Tissue inhibitor matrix metalloproteinase; KIRC, kidney renal clear cell carcinoma; TCGA, The Cancer Genome Atlas.

\section{A}

в
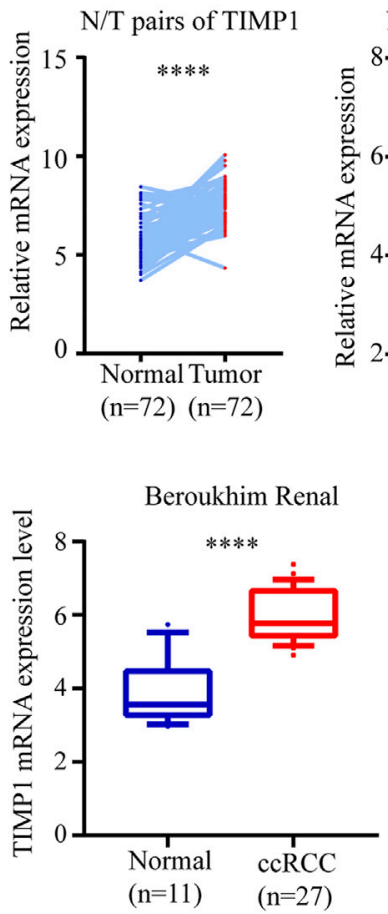

N/T pairs of TIMP2

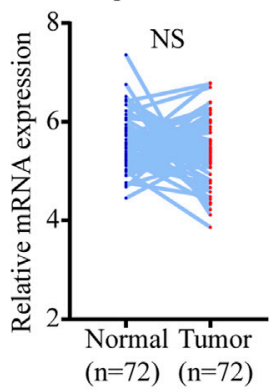

N/T pairs of TIMP4
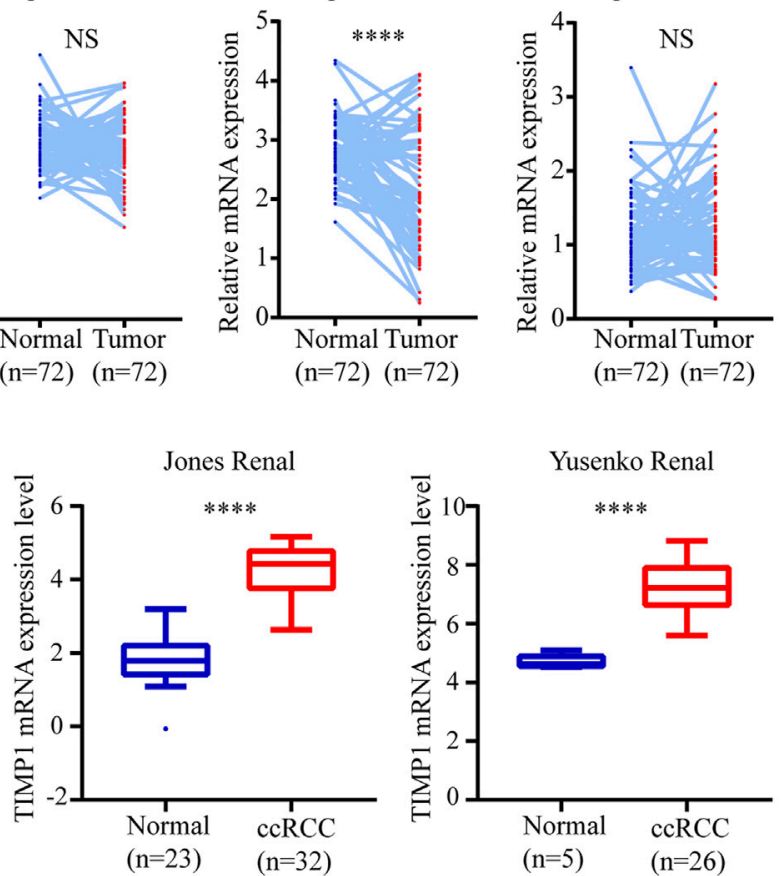

Yusenko Renal

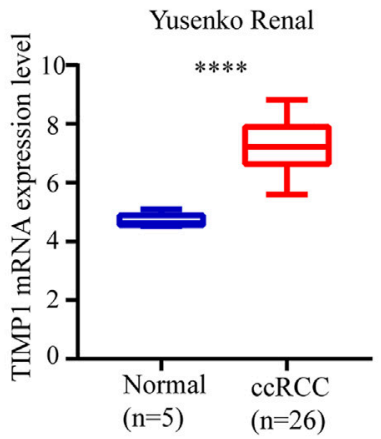

FIGURE 2 | TIMP1 was upregulated in RCC. The mRNA expression level and clinical parameters were downloaded from TCGA_KIRC. (A) mRNA levels of TIMP family proteins in RCC tissues and paired normal tissues. (B) TIMP1 was upregulated in three renal statistics downloaded from the Oncomine database, including Beroukhim, Jones, and Yusenko renal statistics. TIMP, Tissue inhibitor matrix metalloproteinase; TIMP1, Tissue inhibitor matrix metalloproteinase 1; RCC, clear cell renal cell carcinoma, TCGA, The Cancer Genome Atlas; KIRC, kidney renal clear cell carcinoma.

these results indicated that TIMP1 might play an important role in RCC progression, which raised our interest to further study.

\subsection{High Level of TIMP1 Indicated a Poor Clinical Outcome in Subgroups of Patients With Different Clinical Parameters}

Kaplan-Meier survival analysis and log-rank test were applied to determine the OS and DFS in patients with RCC. The result showed that patients with higher levels of TIMP1 had a poorer outcome (Figure 3A). Further Kaplan-Meier survival analysis for subgroups of patients with different clinical parameters demonstrated that TIMP1 was an ideal prognostic biomarker for patients with the following characteristics: T1+T2 stage (Figure 3B), N0 (Figure 3C), M0 (Figure 3D), G1+G2 stage (Figure 3E), age $<60$ (Figure 3F), age $\geq 60$ (Figure 3G), male (Figure 3H) and female (Figure 3I). The DFS survival analysis revealed that patients with higher TIMP1 had a shorter disease-free time (Figure 4A), and TIMP1 could act as a biomarker for patients with the following characteristics: $\mathrm{T} 1+\mathrm{T} 2$ (Figure 4B), N0 (Figure 4C), age $\geq 60$ (Figure 4D), and female (Figure 4E). Furthermore, we applied univariate and multivariate regression models to assess the integrated prognostic value of TIMP1. The results suggested that TIMP1 independently 

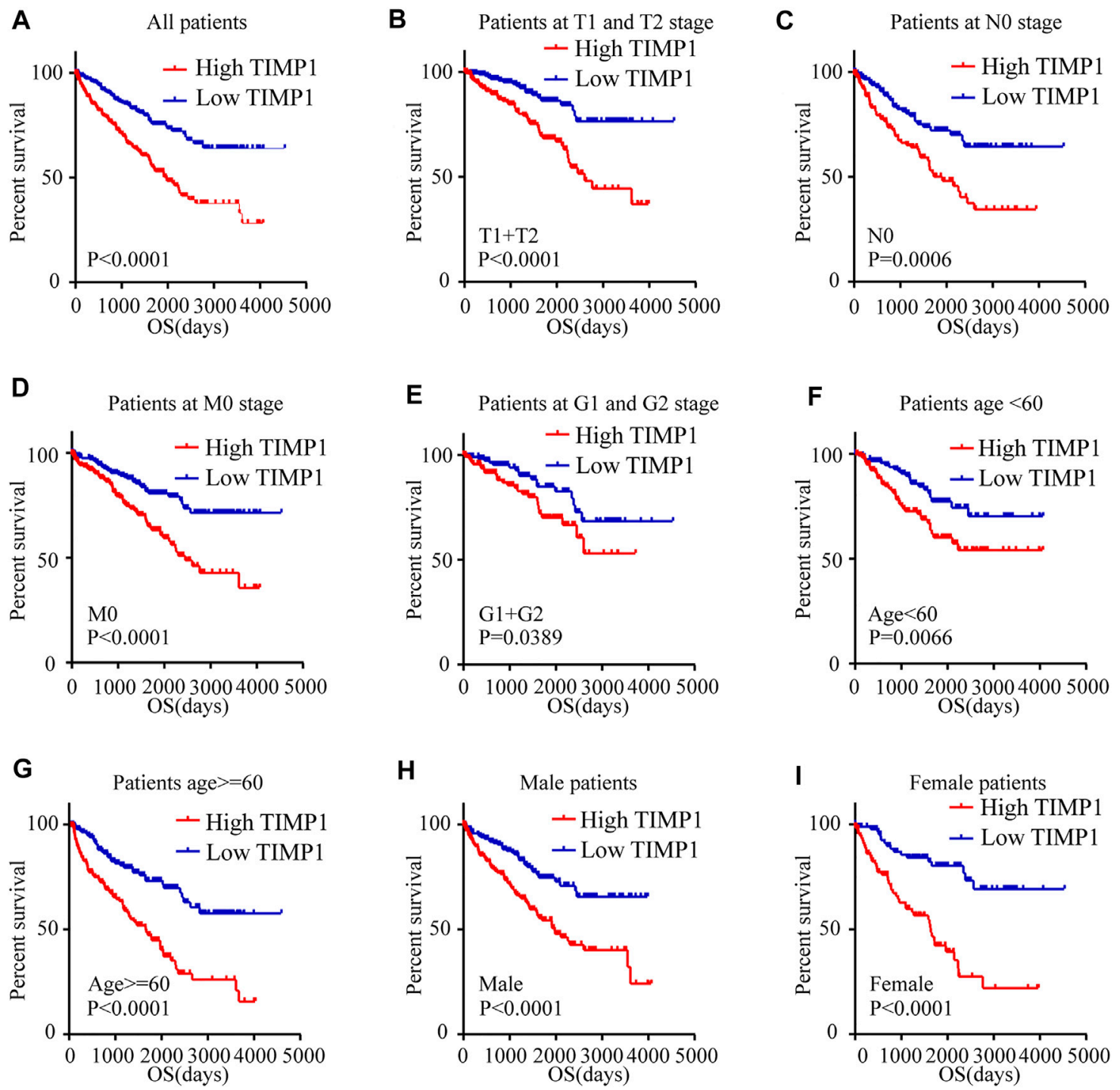

FIGURE 3 | High level of TIMP1 indicated poor OS of patients with RCC. Kaplan-Meier curves for overall survival (OS) were performed in patients with RCC based on the TCGA database. (A) OS was closely associated with TIMP1 levels. OS subanalysis was applied in patients with different clinical parameters. (B) Patients at T1 and T2 stage, (C) Patients at N0 stage, (D) Patients at M0 stage, (E) Patients at G1 and G2 stage, (F) Patient with age $<60$, (G) Patients with age $\geq 60$, (H) Male patients, (I) Female patients. TIMP1, Tissue inhibitor matrix metalloproteinase 1; RCC, renal cell carcinoma; TCGA, The Cancer Genome Atlas.

correlated with the OS and DFS status of RCC patients (Tables 2, 3). In conclusion, the above results demonstrated that the high level of TIMP1 indicated a poor clinical outcome and TIMP1 could serve as an ideal prognostic biomarker for RCC.

\subsection{TIMP1 Expression Level Was Associated With Different Clinicopathological Parameters}

To clarify the expression pattern of TIMP1 in patients with different clinical parameters, the present study analyzed the TIMP1 expression levels of 522 cases from the TCGA database. The results confirmed that the high expression level of TIMP1 is associated with patients' gender, higher $\mathrm{T}$ stage, $\mathrm{N}$ stage, $\mathrm{M}$ stage,
TNM stage, and histological grade (Figures 5A-F). Besides, patients with worse OS status and DFS status had a higher level of TIMP1 expression (Figures 5G,H). However, there were no obvious differences between patients aged $\geq 60$ years and those aged $<60$ years (Table 4). These results demonstrated that TIMP1 was upregulated and closely related to gender, $\mathrm{T}$ stage, $\mathrm{N}$ stage, $\mathrm{M}$ stage, TNM stage, and histological grade in RCC.

\subsection{The mRNA Expression Level of TIMP1 can Serve as a Biomarker for Clinical RCC Diagnosis}

To access the value of TIMP1 mRNA expression level in the diagnosis of RCC, receiver operating characteristic (ROC) 
A

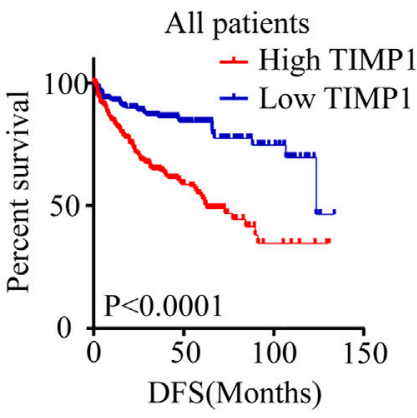

B Patients at $\mathrm{T} 1$ and $\mathrm{T} 2$ stage

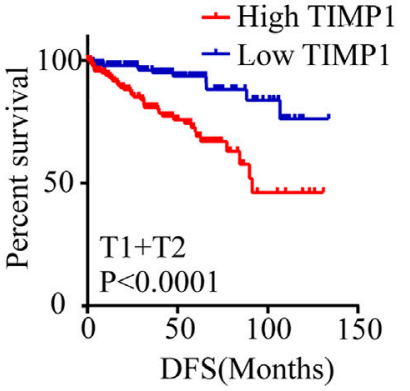

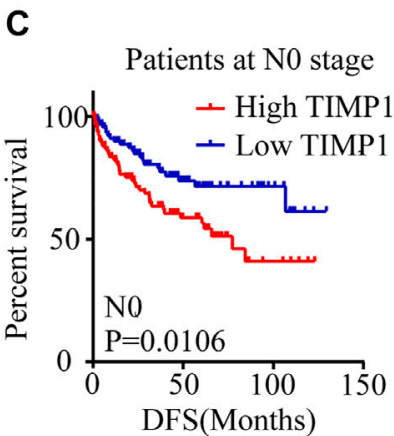

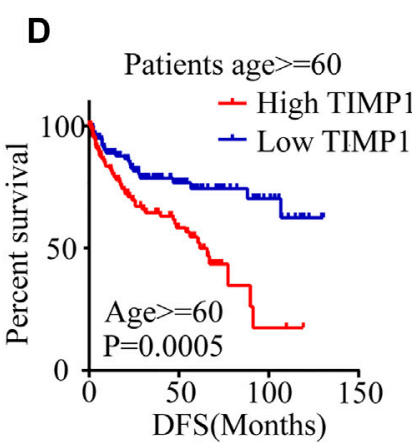

E Female patients

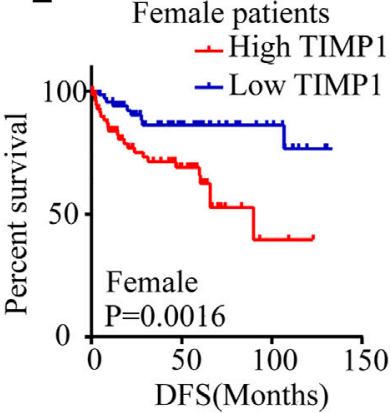

FIGURE 4 | High level of TIMP1 suggested poor DFS of patients with RCC. Kaplan-Meier curves for disease-free survival (DFS) were performed in patients with RCC. (A) High level of TIMP1 indicated poor DFS. Kaplan-Meier curves for DFS as determined by different clinical parameters in RCC. (B) Patients at T1 and T2 stage, (C) Patients at N0 stage, (D) Patients with age $\geq 60$, (E) Female patients. TIMP1, Tissue inhibitor matrix metalloproteinase 1; RCC, renal cell carcinoma; TCGA, The Cancer Genome Atlas.

TABLE 2 | Univariate and multivariate analyses of TIMP1 mRNA level and patient overall survival.

\begin{tabular}{|c|c|c|c|c|c|c|}
\hline \multirow[t]{2}{*}{ Variable } & \multicolumn{3}{|c|}{ Univariate analysis } & \multicolumn{3}{|c|}{ Multivariate analysis $^{a}$} \\
\hline & HR & $95 \% \mathrm{Cl}$ & $p$-value & $H R^{b}$ & $95 \% \mathrm{Cl}^{\mathrm{c}}$ & $p$-value \\
\hline \multicolumn{7}{|c|}{ Overall survival $(n=522)$} \\
\hline Age (years) & 1.786 & $1.312-2.450$ & $<0.001$ & 1.600 & $1.159-2.209$ & 0.004 \\
\hline Gender & 0.933 & $0.683-1.275$ & 0.663 & & & \\
\hline T stage & 3.209 & $2.361-4.364$ & $<0.001$ & 1.572 & $1.089-2.270$ & 0.016 \\
\hline $\mathrm{N}$ stage & 3.944 & $2.135-7.285$ & $<0.001$ & 1.998 & $1.060-4.136$ & 0.032 \\
\hline
\end{tabular}

a Multivariate models were adjusted for TIMP1, T, N, M, G classification, and age.

${ }^{b}$ Hazard ratio, estimated from Cox proportional hazard regression model.

${ }^{c}$ Confidence interval of the estimated HR.

curves were applied for patients with different clinicopathological variables. Area under curve (AUC) was used to evaluate the diagnostic efficiency. The results indicated that TIMP1 could adequately distinguish RCC patients with an AUC of 0.8858 ( $p<0.0001$; Figure 6A). Additionally, the TIMP1 expression level also exhibited diagnostic value for subgroups of patients with RCC as follows: $\mathrm{T} 1+\mathrm{T} 2$ vs. T3+T4 (AUC $=0.6414, p<0.0001$; Figure 6B), G1+G2 vs. G3+G4 (AUC = 0.6307, $p<0.0001$; Figure $6 \mathrm{C}$ ), $\mathrm{M} 0$ vs. $\mathrm{M} 1$ stage $(\mathrm{AUC}=0.6375, p=0.0001$; Figure 6D), TNM I + II vs TNM III + IV stage $(\mathrm{AUC}=0.6546$, $p<0.0001$; Figure 6E), OS good vs. OS poor $(\mathrm{AUC}=0.6617$, $p<0.0001$; Figure 6F), DFS good vs DFS poor $(\mathrm{AUC}=0.7056$, $p<0.0001$; Figure 6G) and male vs. female (AUC $=0.5875, p=$ 0.001 ; Figure $6 \mathbf{H})$. Therefore, TIMP1 might act as a potential biomarker for RCC diagnosis.

\subsection{TIMP1 Was Upregulated in RCC Cell Lines and Tissues}

To further confirm the results from bioinformatics analysis, we performed a quantitative real-time polymerase chain reaction 
TABLE 3 | Univariate and multivariate analyses of TIMP1 mRNA level and patient disease-free survival.

\begin{tabular}{|c|c|c|c|c|c|c|}
\hline \multirow[t]{2}{*}{ Variable } & \multicolumn{3}{|c|}{ Univariate analysis } & \multicolumn{3}{|c|}{ Multivariate analysis ${ }^{a}$} \\
\hline & HR & $95 \% \mathrm{Cl}$ & $p$-value & $H_{R^{b}}$ & $95 \% \mathrm{Cl}^{\mathrm{c}}$ & $p$-value \\
\hline \multicolumn{7}{|l|}{ DFS $(n=428)$} \\
\hline TIMP1 & 2.999 & $2.024-4.442$ & $<0.001$ & 2.104 & $1.364-3.245$ & 0.001 \\
\hline Age (years) & 1.364 & $0.956-1.946$ & 0.086 & & & \\
\hline Gender & 1.421 & $0.957-2.112$ & 0.082 & & & \\
\hline T stage & 4.571 & $3.164-6.603$ & $<0.001$ & 1.954 & $1.275-2.996$ & 0.002 \\
\hline N stage & 6.024 & $3.024-11.997$ & $<0.001$ & 2.833 & $1.390-5.774$ & 0.004 \\
\hline M stage & 8.522 & $5.870-12.372$ & $<0.001$ & 4.999 & $3.317-7.681$ & $<0.001$ \\
\hline G grade & 3.426 & $2.269-5.172$ & $<0.001$ & 2.124 & $1.363-3.309$ & 0.001 \\
\hline
\end{tabular}

a Multivariate models were adjusted for TIMP1, T, N, M, G classification.

${ }^{b}$ Hazard ratio, estimated from Cox proportional hazard regression model.

${ }^{c}$ Confidence interval of the estimated HR.

(qRT-PCR) analysis and western blot in RCC cell lines and tissues. We found a significantly higher level of TIMP1 mRNA in RCC cells (786-O, ACHN, A498, CAKI-1, OSRC-2) relative to HK-2 (Figure 7A). Western blot revealed that the expression level of TIMP1 in RCC was higher compared with HK-2 (Figure 7B). Then we studied the expression of TIMP1 mRNA and protein in tissues. We detected 20 pairs of RCC tissues and corresponding adjacent normal tissues for qRT-PCR and found TIMP1 over-expression in RCC in 17 pairs of tissues (Figure 7C). Western blot for tissues showed a similar result. TIMP1 expression was significantly higher in RCC compared with adjacent normal tissues (Figure 7D). Furthermore, IHC was conducted in 3 pairs of RCC tissues and adjacent normal tissues. TIMP1 was primarily located in the membranes and cytoplasm of cancer cells and renal tubular epithelial cells (Figure 7E). The results proved that the expression of TIMP1 was higher in RCC tissues again. These findings confirmed that TIMP1 was upregulated in RCC cells and tissues.

\subsection{TIMP1 Promoted the Proliferation, Migration, and Invasion of RCC Cells}

In order to elucidate the function of TIMP1 in RCC, TIMP1 was knocked down by TIMP1-siRNA and was overexpressed by transfecting plasmid into ACHN and 786-O cell lines. Then we used qRT-PCR and western blot to test the efficiency of transfection. The results showed that TIMP1-siRNA and plasmid carrying TIMP1 could raise corresponding effects on TIMP1 expression in cells (Figures 8A,B). CCK8 assays revealed that TIMP1 knockdown could significantly repress the proliferation rates of $\mathrm{ACHN}$ and 786-O, while overexpression of TIMP1 accelerated cell proliferation (Figures 8C,D). We applied transwell assays to detect the influence of TIMP1 on RCC cells' migration and invasion ability. The results showed that TIMP1 knockdown suppressed the migration and invasion ability of ACHN and 786-O, while TIMP1 overexpression promoted these features (Figures 9E,F). In conclusion, TIMP1 facilitated the progression of RCC by promoting the proliferation, migration, and invasion of RCC cells.

\subsection{TIMP1 Was Involved in Multiple Biological Processes and Promoted RCC via the Epithelial-To-Mesenchymal Transition Pathway}

To clarify the specific function of TIMP1 in RCC, GSEA based on the TCGA database was performed. Besides, we retrieved the biological process of TIMP1 in STRING (https://string-db.org/). The results of GSEA have shown that TIMP1 was closely related to tumorigenesis, metastasis, cell cycles, and epithelial-tomesenchymal transition (Figures 9A-F). The protein-protein interaction network calculated by STRING displayed the proteins interacting with TIMP1 (Figure 9G). The major GO term included signaling transduction and cell migration (Figure 9H; Table 5). The KEGG pathways TIMP1 participated in involved PI3K-Akt and JAK-STAT signaling pathways (Figure 9I; Table 6). These results indicated that TIMP1 might play a key role in the metastasis of RCC and participate in extracellular signal transduction. According to the information above, we examined the EMT pathway which was proved to be critical in tumor metastasis by silencing TIMP1. The results revealed that TIMP1 silencing led to the downregulation of $\mathrm{N}$-cadherin and upregulation of E-cadherin (Figure 9J). These findings illustrated that TIMP1 facilitated the progression of RCC via EMT transition.

\section{DISCUSSION}

RCC is one of the most common malignant tumors in the urinary system and accounts for $1.8 \%$ of deaths from cancers (Bray et al., 2018; Wan et al., 2019a; Wan et al., 2019b; Luo et al., 2019; Xu et al., 2019; Zhang et al., 2019; Zhou et al., 2019). So far, there is no effective systemic therapy. Due to the lack of effective tumor markers for early screening and the mild symptoms of early-stage RCC, $1 / 3$ patients have ectopic metastases when diagnosed (Gong et al., 2016). For patients with distant metastases, first-line treatments mainly include surgical resections and TKI inhibitors such as sunitinib, pazopanib, and axitinib (Rini et al., 2011). There are also phase 3 clinical trials showing that everolimus (a mTOR inhibitor), compared with placebo, has a 

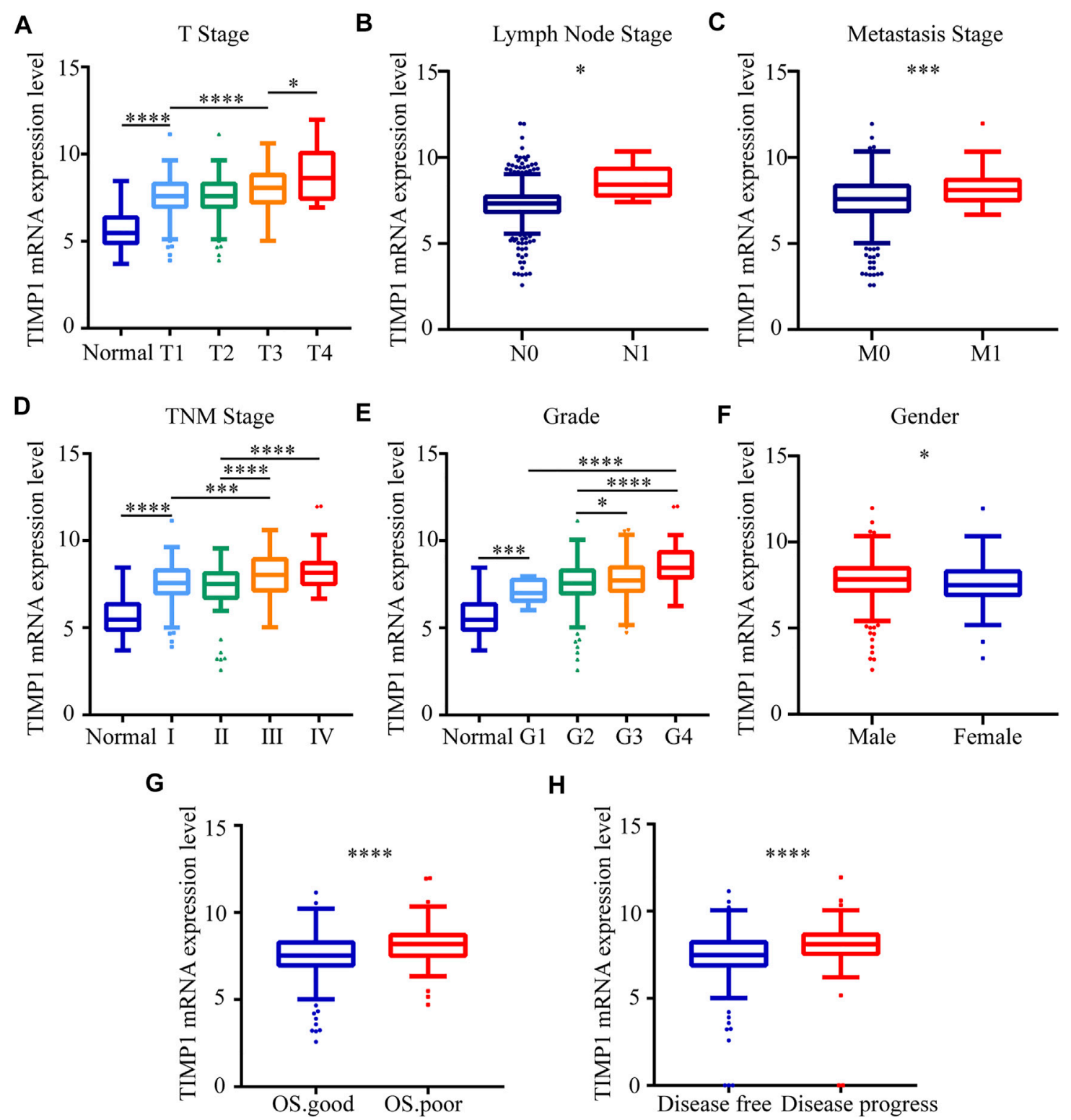

FIGURE 5 | TIMP1 expression level was associated with different clinicopathological parameters. The mRNA expression levels of TIMP1 were downloaded from the TCGA-KIRC database. TIMP1 was upregulated in (A) T stage, (B) lymph node metastasis, (C) distant metastases, (D) TNM stage, (E) G grade, (F) gender, (G) OS status, (H) DFS status. ${ }^{\star \star \star \star} p<0.0001 ;{ }^{\star \star \star} p<0.001 ;{ }^{\star} p<0.05$. TIMP1, Tissue inhibitor matrix metalloproteinase 1 ; RCC, clear cell renal cell carcinoma; KIRC, kidney renal clear cell carcinoma; TCGA, The Cancer Genome Atlas; TNM, Tumor-Node-Metastasis; OS, overall survival; DFS, disease-free survival.

longer disease-free survival (Choueiri et al., 2015; Motzer et al., 2015; Cella et al., 2016). However, the development of drug resistance leads to their failure and brings some adverse reactions such as liver toxicity, hand-foot syndrome, etc (Motzer et al., 2013). Thus, detecting RCC at early stage is of most importance for improving patients' survival by far.

Some most recent researches showed RAC2, LINC00160, IGFL2-AS1, AC023043.1 could serve as biomarkers for diagnosing RCC (Cheng et al., 2019; Liu et al., 2019; Cheng et al., 2020). In the present study, we selected the members of the TIMP family, which encoded the natural inhibitors for MMPs.
We found an independent prognostic factor for RCC, TIMP1, by using bioinformatics analysis. We discovered that TIMP1 was significantly up-regulated in RCC and patients with a higher level of TIMP1 had worse clinical outcomes. ROC analysis revealed that TIMP1 could distinguish RCC patients from normal people. Meanwhile, TIMP1, as a secreted protein, could be detected in blood and other body fluid. So TIMP1 might be an ideal biomarker for RCC according to these findings.

Related research showed that TIMP1 could inhibit the proteolytic activity of matrix metalloproteinases (MMPs) by forming noncovalent 1:1 stoichiometric complex and regulate 
TABLE 4 | Correlation between TIMP1 mRNA expression and clinicopathological parameters of ccRCC patients.

\begin{tabular}{|c|c|c|c|c|c|}
\hline \multirow[t]{2}{*}{ Parameter } & & \multirow[t]{2}{*}{ Number } & \multicolumn{2}{|c|}{ TIMP1 mRNA expression } & \multirow[t]{2}{*}{$p$ Value } \\
\hline & & & Low $(n=261)$ & High $(n=261)$ & \\
\hline \multirow[t]{2}{*}{ Age (years) } & $<60$ & 244 & 119 & 125 & 0.599 \\
\hline & $\geq 60$ & 278 & 142 & 136 & \\
\hline \multirow[t]{2}{*}{ Gender } & Female & 180 & 105 & 75 & $0.006^{a}$ \\
\hline & Male & 342 & 156 & 186 & \\
\hline \multirow[t]{2}{*}{ T stage } & $\mathrm{T} 1$ or $\mathrm{T} 2$ & 335 & 190 & 145 & $<0.001^{a}$ \\
\hline & T3 or T4 & 187 & 71 & 116 & \\
\hline \multirow[t]{2}{*}{ N stage } & NO or NX & 507 & 258 & 249 & $0.018^{a}$ \\
\hline & $\mathrm{N} 1$ & 15 & 3 & 12 & \\
\hline \multirow[t]{2}{*}{ M stage } & MO or MX & 445 & 237 & 208 & $<0.001^{a}$ \\
\hline & M1 & 77 & 24 & 53 & \\
\hline \multirow[t]{2}{*}{ G grade } & $\mathrm{G} 1$ or $\mathrm{G} 2$ or $\mathrm{Gx}$ & 245 & 146 & 99 & $<0.001^{a}$ \\
\hline & G3 or G4 & 277 & 115 & 162 & \\
\hline \multirow[t]{2}{*}{ TNM stage } & $1+\|$ & 317 & 186 & 131 & $<0.001^{a}$ \\
\hline & $I I I+I V$ & 205 & 75 & 130 & \\
\hline
\end{tabular}

${ }^{a} p<0.05$.

A

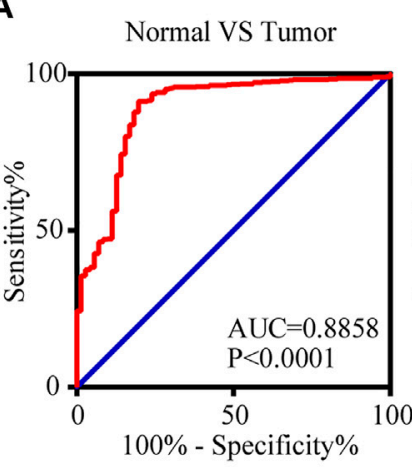

B

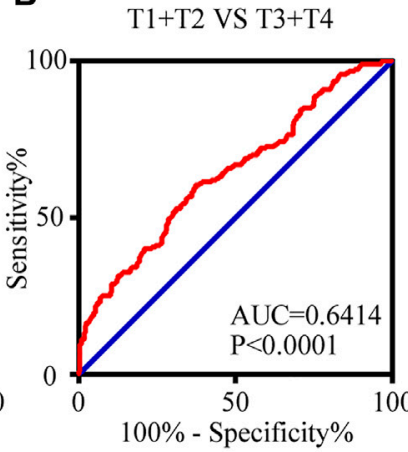

E

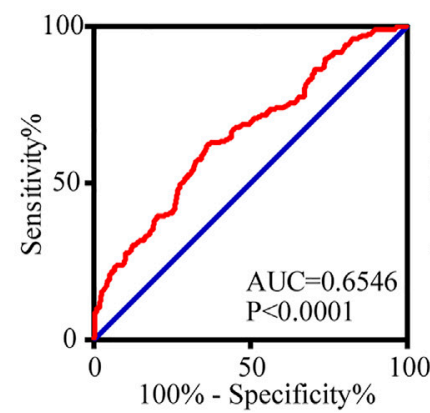

\section{F OS.good VS OS.poor}

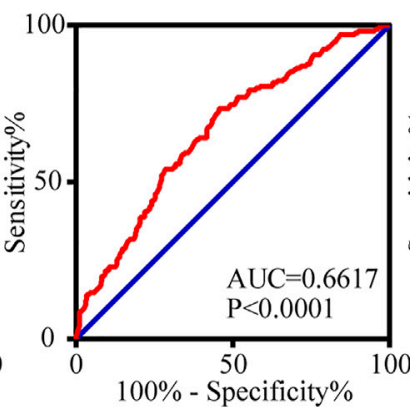

C

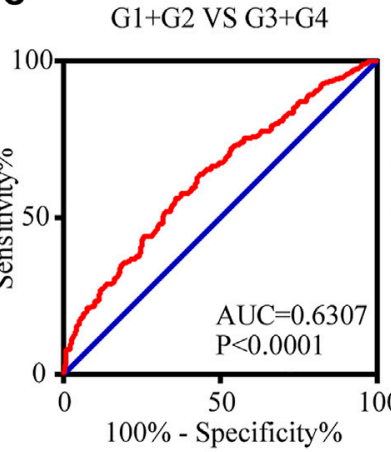

D

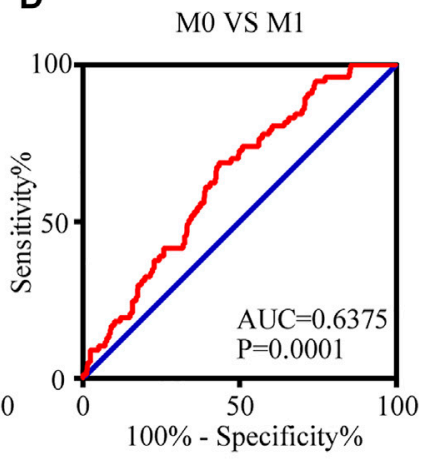

G

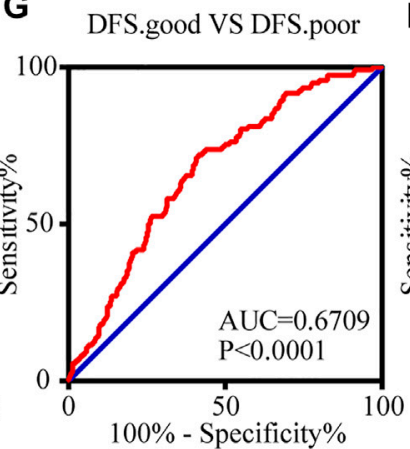

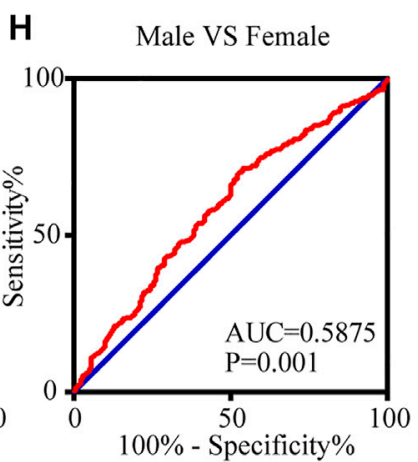

FIGURE 6 | The mRNA expression level of TIMP1 can serve as a biomarker for clinical RCC diagnosis. (A) TIMP1 could effectively distinguish RCC from normal tissues (AUC = 0.8858; $p<0.0001$ ). ROC analysis was performed in the following subgroups of patients with RCC: (B) T grade, (C) G stage, (D) distant metastases, (E) TNM stage, (F) OS status, (G) DFS status and (H) gender. TIMP1, Tissue inhibitor matrix metalloproteinase 1; RCC, clear cell renal cell carcinoma; ROC, Receiver operating curve, AUC, area under the curve; OS, overall survival; DFS, disease-free survival.

the balance of matrix remodeling during degradation of extracellular matrix (Batra et al., 2012). However, the most recent studies revealed other important biological functions of TIMP1 including anti-apoptosis, anti-angiogenesis, cell cycle regulation, and differentiation activities. TIMP1 activated hepatic stellate cells via CD63 signaling to create a premetastatic niche in pancreatic cancer (Grunwald et al., 2016). Down-regulation of TIMP1 was found to enhance gemcitabine sensitivity and reverse chemoresistance in pancreatic cancer (Tan et al., 2020). TIMP1 was involved in 
A

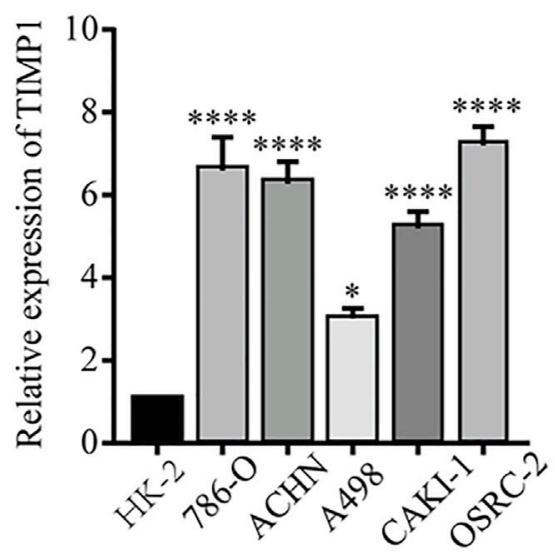

C

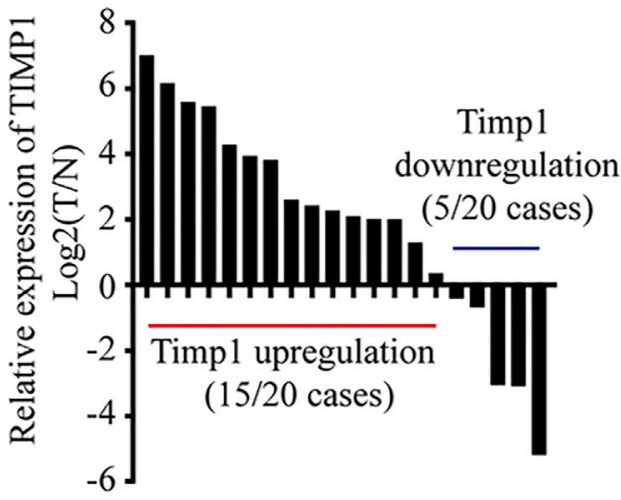

E

Case1
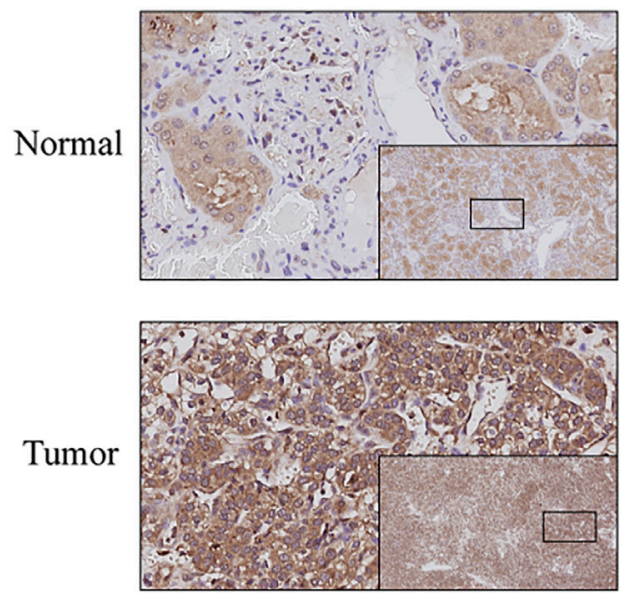

B

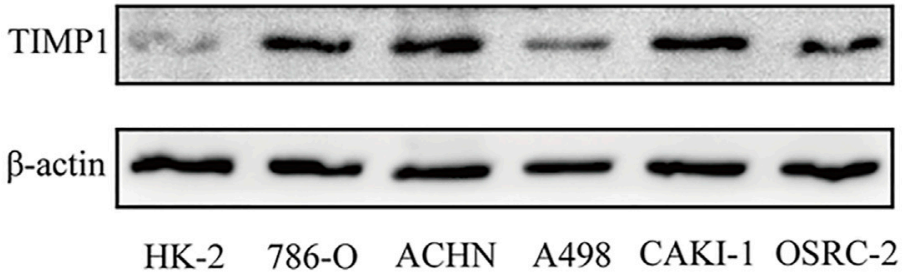

D

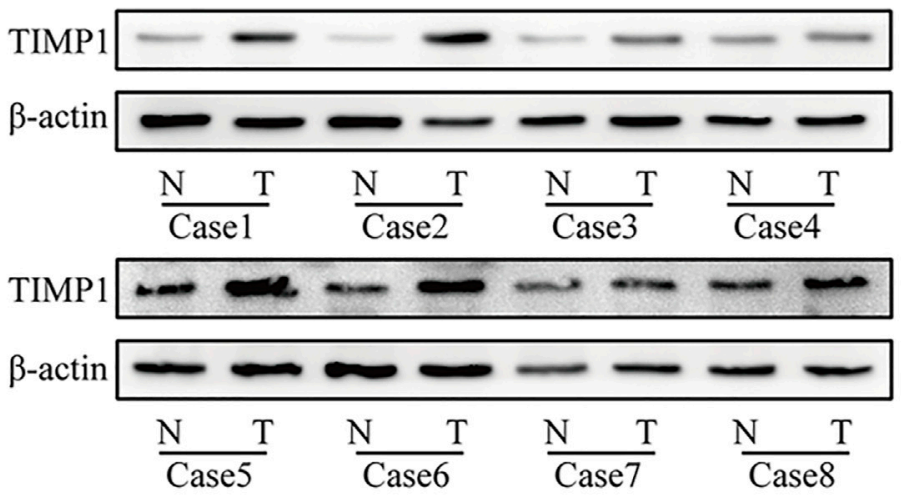

FIGURE 7 | TIMP1 was upregulated in RCC cell lines and tissues. (A) Levels of TIMP1 mRNA in 5 renal cancer cell lines (786-O, ACHN, A498, CAKI-1, OSRC-2) and a normal cell line (HK-2). (B) Levels of TIMP1 protein in 5 renal cancer cell lines (786-O, ACHN, A498, CAKI-1, OSRC-2) and a normal cell line (HK-2). (C) The mRNA levels of TIMP1 in 20 RCC tissues and adjacent nonmalignant tissues. (D) The protein levels of TIMP1 in RCC tissues and adjacent nonmalignant tissues. (E) Immunohistochemical (IHC) staining for TIMP1 in RCC tissues and adjacent nonmalignant tissues. The images are the lower magnification of the same tissue as that presented in the larger image of each set. Magnification, $\times 100$ and $\times 400$. TIMP1 expression was normalized to $\beta$-actin expression. ${ }^{\star \star \star *} p<0.0001 ;{ }^{\star} p<0.05$. TIMP1, Tissue inhibitor matrix metalloproteinase 1 RCC, clear cell renal cell carcinoma. 


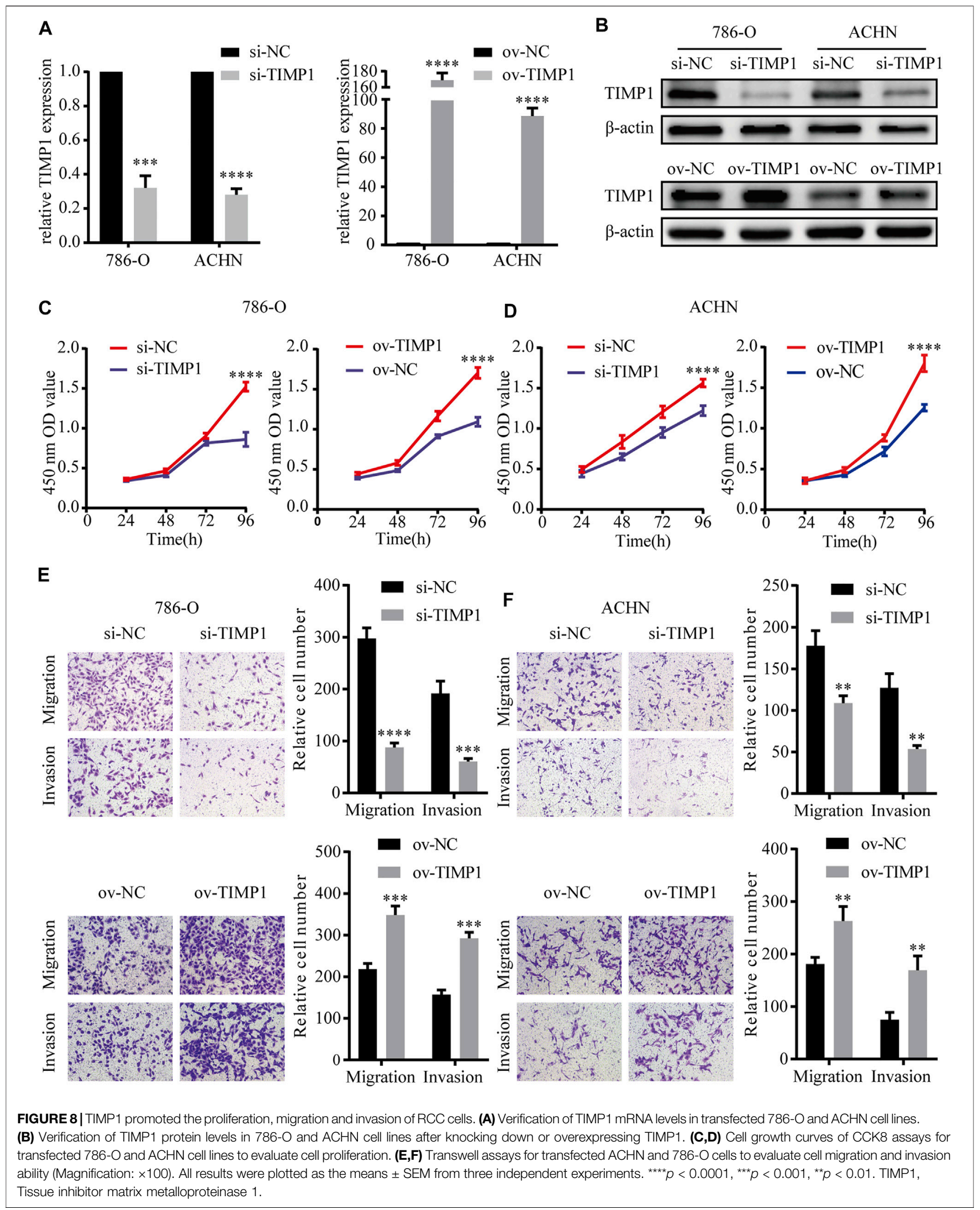




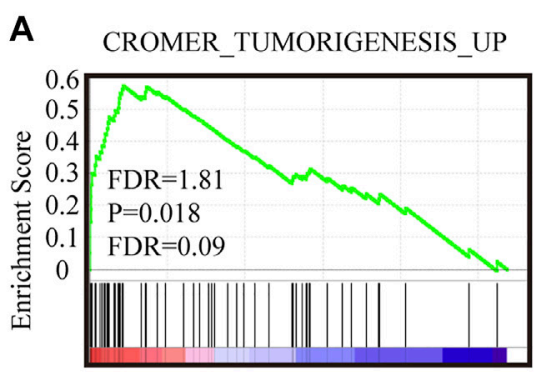

High TIMP1

D JECHLINGER_EPITHELIAL_TO_ MESENCHYMAL_TRANSITION_UP

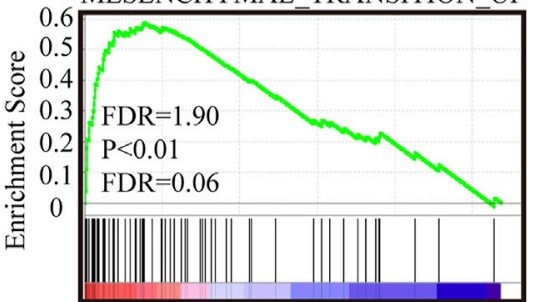

High TIMP1

G

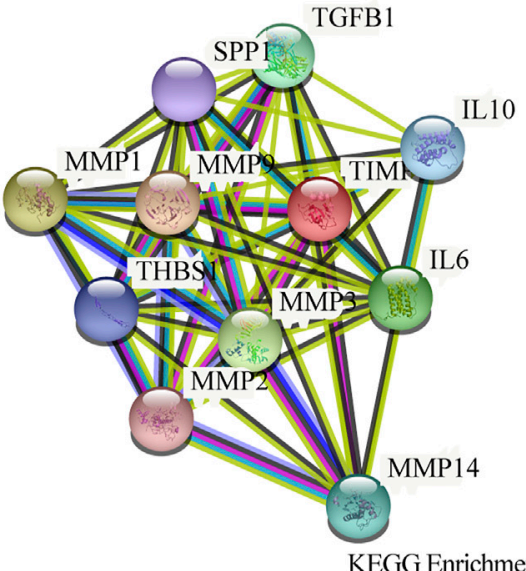

Transcriptional misregulation in cancer-

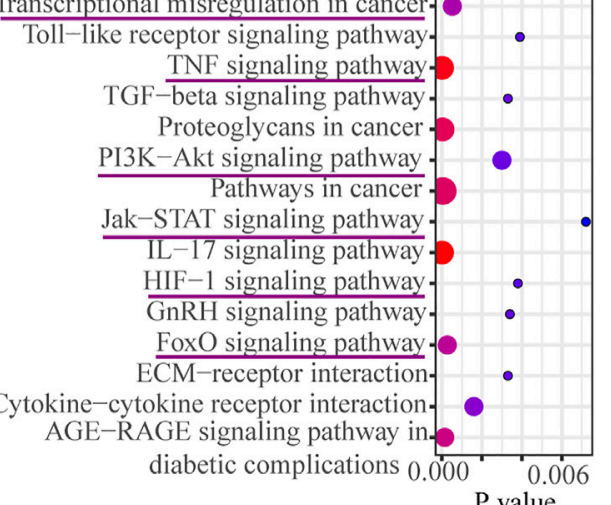

$-\log (\mathrm{P}$ value $)$

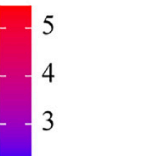

Count

- 2

3

4

5

High TIMP1

High TIMP1

GILDEA_METASTASIS

REACTOME CELL CYCLE CHECKPOINTS

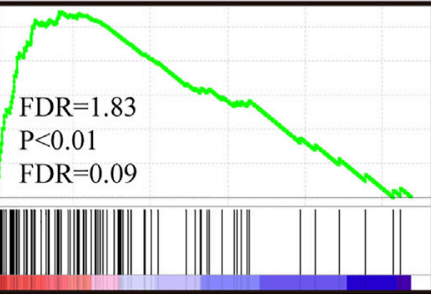

Low TIMP1

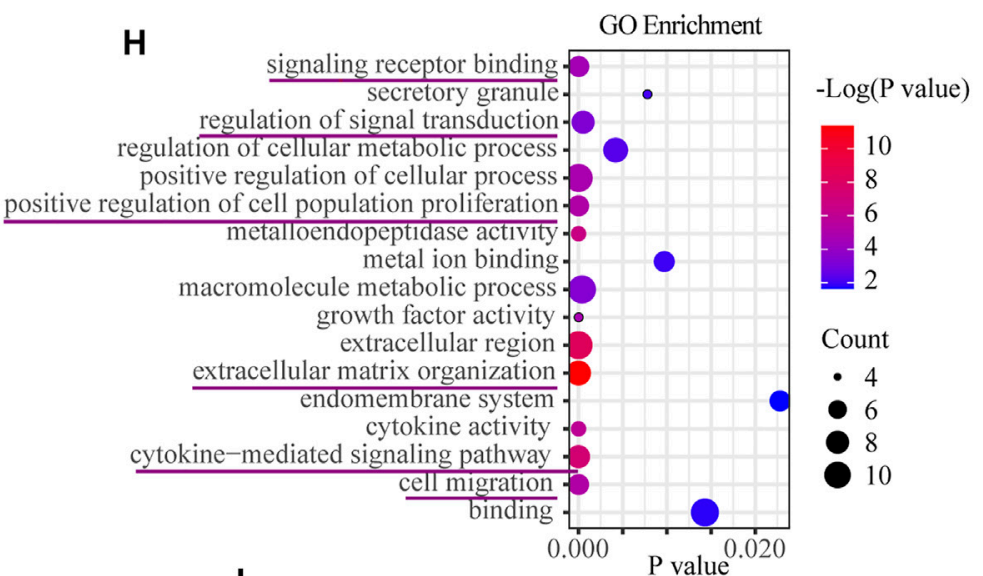

\section{J}

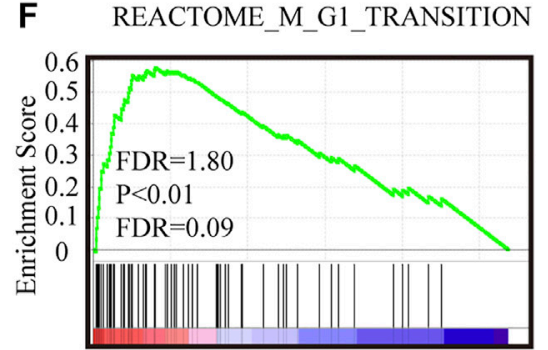

High TIMPI

Low TIMP1

C GOTZMANN_EPITHELIAL_TO
MESENCHYMAL TRANSITION

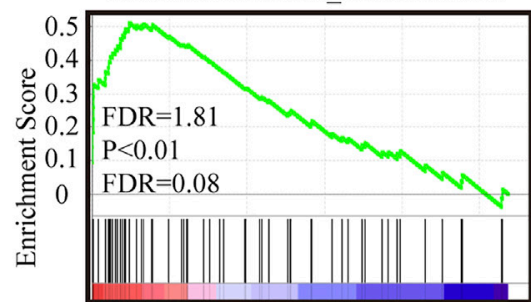

High TIMP1

Low TIMP1

F REACTOME M G1 TRANSITION

GO Enrichment

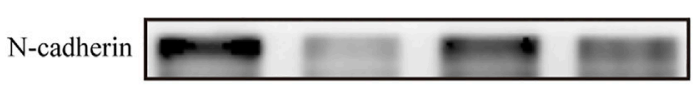

E-cadherin

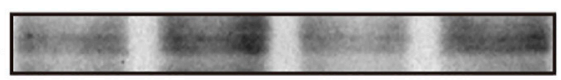

TIMP1

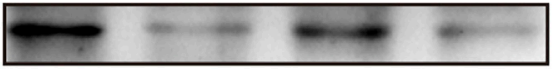

$\beta$-actin

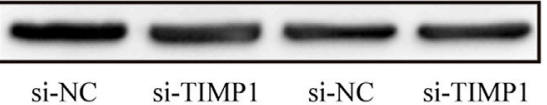

FIGURE 9 | TIMP1 was involved in multiple biological processes and promoted RCC via EMT pathway. (A-F) GSEA analysis for the correlations between the biological pathways with the levels of the TIMP1 mRNA based on TCGA database. FDR $<25 \%$ and $p<0.05$ were considered statistically significant. (G) The proteinprotein interaction network of TIMP1. $(\mathbf{H}, \mathbf{l})$ Biological processes and KEGG pathways in STRING. (J) Verification of N-cadherin and E-cadherin protein changes after silencing TIMP1 in 786-O and ACHN. TIMP1, Tissue inhibitor matrix metalloproteinase 1, KEGG (Kyoto Encyclopedia of Genes and Genomes). 
TABLE 5 | GO enrichment of TIMP1 retrieved from the STRING database.

\begin{tabular}{|c|c|c|c|c|c|}
\hline Term ID & Term description & $\begin{array}{c}\text { Observed } \\
\text { gene } \\
\text { count }\end{array}$ & $\begin{array}{c}\text { Background } \\
\text { gene } \\
\text { count }\end{array}$ & FDR & Matching proteins \\
\hline $\begin{array}{l}\text { GO: } \\
0030198\end{array}$ & Extracellular matrix organization & 7 & 296 & $\begin{array}{l}4.32 \mathrm{E}- \\
12\end{array}$ & $\begin{array}{l}\text { TIMP1, MMP2, TGFB1, THBS1, MMP3, MMP14, MMP1, } \\
\text { MMP9, SPP1 }\end{array}$ \\
\hline $\begin{array}{l}\text { GO: } \\
0019221\end{array}$ & Cytokine-mediated signaling pathway & 11 & 655 & $\begin{array}{l}5.25 E- \\
08\end{array}$ & TIMP1, MMP2, TGFB1, MMP3, MMP1, MMP9, IL6, IL10 \\
\hline $\begin{array}{l}\text { GO: } \\
0016477\end{array}$ & Cell migration & 7 & 812 & $\begin{array}{l}6.15 E- \\
06\end{array}$ & TGFB1, THBS1, MMP14, MMP1, MMP9, IL6, IL10 \\
\hline $\begin{array}{l}\text { GO: } \\
0048522\end{array}$ & Positive regulation of cellular process & 11 & 4898 & $\begin{array}{l}1.47 \mathrm{E}- \\
05\end{array}$ & $\begin{array}{l}\text { TIMP1, MMP2, TGFB1, THBS1, MMP3, MMP14, MMP1, } \\
\text { MMP9, SPP1, IL6, IL10 }\end{array}$ \\
\hline $\begin{array}{l}\text { GO: } \\
0008284\end{array}$ & $\begin{array}{l}\text { Positive regulation of cell population } \\
\text { proliferation }\end{array}$ & 8 & 878 & $\begin{array}{c}7.74 \mathrm{E}- \\
06\end{array}$ & TIMP1, MMP2, TGFB1, THBS1, MMP9, IL6, IL10 \\
\hline $\begin{array}{l}\text { GO: } \\
0043170\end{array}$ & Macromolecule metabolic process & 9 & 7453 & 0.00039 & $\begin{array}{l}\text { TIMP1, MMP2, TGFB1, THBS1, MMP3, MMP14, MMP1, } \\
\text { MMP9, SPP1, IL6, IL10 }\end{array}$ \\
\hline $\begin{array}{l}\text { GO: } \\
0009966\end{array}$ & Regulation of signal transduction & 11 & 3033 & 0.00052 & TIMP1, TGFB1, THBS1, MMP14, MMP9, SPP1, IL6, IL10 \\
\hline $\begin{array}{l}\text { GO: } \\
0031323\end{array}$ & Regulation of cellular metabolic process & 8 & 6082 & 0.0042 & $\begin{array}{l}\text { TIMP1, TGFB1, THBS1, MMP3, MMP14, MMP9, SPP1, IL6, } \\
\text { IL10 }\end{array}$ \\
\hline $\begin{array}{l}\text { GO: } \\
0005576\end{array}$ & Extracellular region & 9 & 2505 & $\begin{array}{l}4.08 \mathrm{E}- \\
09\end{array}$ & $\begin{array}{l}\text { TIMP1, MMP2, TGFB1, THBS1, MMP3, MMP14, MMP1, } \\
\text { MMP9, SPP1, IL6, IL10 }\end{array}$ \\
\hline $\begin{array}{l}\text { GO: } \\
0012505\end{array}$ & Endomembrane system & 11 & 4347 & 0.0228 & TIMP1, TGFB1, THBS1, MMP14, MMP9, SPP1, IL6 \\
\hline $\begin{array}{l}\text { GO: } \\
0004222\end{array}$ & Metalloendopeptidase activity & 7 & 110 & $\begin{array}{c}2.39 \mathrm{E}- \\
07\end{array}$ & MMP2, MMP3, MMP14, MMP1, MMP9 \\
\hline $\begin{array}{l}\text { GO: } \\
0005125\end{array}$ & Cytokine activity & 5 & 216 & $\begin{array}{l}1.31 \mathrm{E}- \\
05\end{array}$ & TIMP1, TGFB1, SPP1, IL6, IL10 \\
\hline $\begin{array}{l}\text { GO: } \\
0008083\end{array}$ & Growth factor activity & 4 & 160 & $\begin{array}{l}1.77 \mathrm{E}- \\
05\end{array}$ & TIMP1, TGFB1, IL6, IL10 \\
\hline $\begin{array}{l}\text { GO: } \\
0046872\end{array}$ & Metal ion binding & 7 & 4087 & 0.0097 & TIMP1, MMP2, THBS1, MMP3, MMP14, MMP1, MMP9 \\
\hline $\begin{array}{l}\text { GO: } \\
0005488\end{array}$ & Binding & 11 & 11878 & 0.0143 & $\begin{array}{l}\text { TIMP1, MMP2, TGFB1, THBS1, MMP3, MMP14, MMP1, } \\
\text { MMP9, SPP1, IL6, IL10 }\end{array}$ \\
\hline $\begin{array}{l}\text { GO: } \\
0030141\end{array}$ & Secretory granule & 4 & 828 & 0.0078 & TIMP1, TGFB1, THBS1, MMP9 \\
\hline $\begin{array}{l}\text { GO: } \\
0012505\end{array}$ & Endomembrane system & 7 & 4347 & 0.0228 & TIMP1, TGFB1, THBS1, MMP14, MMP9, SPP1, IL6 \\
\hline
\end{tabular}

GO, gene ontology; TIMP1, Tissue inhibitor matrix metalloproteinase 1; FDR, false discovery rate.

\begin{tabular}{|c|c|c|c|c|c|}
\hline Term ID & Term description & $\begin{array}{l}\text { Observed gene } \\
\text { count }\end{array}$ & $\begin{array}{c}\text { Background gene } \\
\text { count }\end{array}$ & FDR & Matching proteins \\
\hline hsa04657 & IL-17 signaling pathway & 4 & 92 & $3.45 E-06$ & MMP3, MMP1, MMP9, IL6 \\
\hline hsa04668 & TNF signaling pathway & 4 & 108 & $5.13 E-06$ & MMP3, MMP14, MMP9, IL6 \\
\hline hsa05205 & Proteoglycans in cancer & 4 & 195 & 3.19E-05 & MMP2, TGFB1, THBS1, MMP9 \\
\hline hsa05200 & Pathways in cancer & 5 & 515 & 4.61E-05 & MMP2, TGFB1, MMP1, MMP9, IL6 \\
\hline hsa04068 & Fofo signaling pathway & 3 & 130 & 0.00027 & TGFB1, IL6, IL10 \\
\hline hsa05202 & Transcriptional misregulation in cancer & 3 & 169 & 0.00052 & MMP3, MMP9, IL6 \\
\hline hsa04060 & Cytokine-cytokine receptor interaction & 3 & 263 & 0.0016 & TGFB1, IL6, IL10 \\
\hline hsa04151 & PI3K-Act signaling pathway & 3 & 348 & 0.003 & THBS1, SPP1, IL6 \\
\hline hsa04350 & TGF-beta signaling pathway & 2 & 83 & 0.0033 & TGFB1, THBS1 \\
\hline hsa04512 & ECM-receptor interaction & 2 & 81 & 0.0033 & THBS1, SPP1 \\
\hline hsa04912 & GnRH signaling pathway & 2 & 88 & 0.0034 & MMP2, MMP14 \\
\hline hsa04066 & HIF-1 signaling pathway & 2 & 98 & 0.0038 & TIMP1, IL6 \\
\hline hsa04620 & Toll-like receptor signaling pathway & 2 & 102 & 0.0039 & SPP1, IL6 \\
\hline hsa04630 & Jak-STAT signaling pathway & 2 & 160 & 0.0072 & IL6, IL10 \\
\hline hsa04933 & AGE-RAGE signaling pathway in diabetic complications & 3 & 98 & 0.00014 & MMP2, TGFB1, IL6 \\
\hline
\end{tabular}

KEGG, kyoto encyclopedia of genes and genomes; TIMP1. Tissue inhibitor matrix metalloproteinase 1; FDR, false discovery rate. 
angiogenesis in gastric cancer (Li et al., 2020). TIMP1 could even regulate the adipogenesis of adipose-derived stem cells via the WNT signaling pathway (Wang et al., 2020). Besides, TIMP1 was associated with fibrosis and suppression of programmed cell death of B Cells (Guedez et al., 1998; Arthur, 2000; LaRocca et al., 2017). The upregulation of TIMP1 was relative to poor prognosis of multiple cancers including colon cancer, breast cancer, gastric cancer, melanoma, papillary thyroid carcinoma, renal cell carcinoma, and so on (Hawthorn et al., 2004; Wang et al., 2013; Cheng et al., 2016; Song et al., 2016; Zurac et al., 2016).

To further investigate the function of TIMP1 in RCC, we applied qRT-PCR, WB, and IHC to confirm the upregulation of TIMP1 in RCC cells and tissues. Next, we researched the effect of TIMP1 on RCC cells by knocking down and overexpressing TIMP1. The results revealed that TIMP1 promoted proliferation, migration, and invasion of RCC cells. In order to figure out how TIMP1 facilitated RCC progression, we applied GSEA based on TCGA_KIRC and retrieved the biological functions of TIMP1 via STRING. The discovery showed that TIMP1 mainly participated in the regulation of extracellular matrix and closely associate with metastasis, EMT pathway, and some typical signal transduction pathways. Further study indicated that knockdown of TIMP1 led to up-regulation of E-cadherin and down-regulation of $\mathrm{N}$-cadherin, which proved TIMP1 accelerated the progression of RCC via EMT pathway in a MMPs inhibitor-independent manner.

The EMT signal pathway was well known for its critical function in wound healing, tumor metastasis and malignant progression (Dongre and Weinberg, 2019; Brabletz et al., 2021). The cells developed into a quasi-mesenchymal state from the original epithelial state via the EMT pathway, which strengthens the metastatic potential of malignant cells (Kalluri and Weinberg, 2009; Nieto, 2009; Thiery et al., 2009; Nieto et al., 2016). Recent studies showed that TIMPs and MMPs were closely related to the EMT pathway, which supported our findings (Argote Camacho et al., 2021; Nayim et al., 2021). But studies involving the specific mutual effect between TIMP1 and the EMT pathway were rare.

Taking the above findings into consideration, it was reasonable to believe that the most critical function of TIMP1 was to enhance the metastatic ability of RCC cells via the EMT pathway, while the effect of TIMP1 on proliferation might be due to other minor functions of the EMT pathway. All these discoveries showed TIMP1 might be a potential diagnostic and prognostic biomarker for clear cell renal cell carcinoma that facilitated tumor progression. There were still some limitations in the present study. The effect of TIMP1 was not proved in vivo. Besides, the specific mechanism causing the abnormal regulation of TIMP1 was still unclear. Therefore, further study was required to solve these problems.

\section{CONCLUSION}

The present research proved that a high level of TIMP1 expression was associated with a poor clinical outcome. TIMP1 promoted the proliferation, migration, and invasion of RCC cells and facilitated the progression of RCC via the EMT pathway. We proved that the biological effects of TIMP1 mediated by signal transduction pathways were far more than those previously known as MMP inhibitors. The aforementioned results indicated that TIMP1 may be an ideal diagnostic and prognostic biomarker for RCC, and molecular targets for TIMP1 might provide a new choice for RCC treatment.

\section{DATA AVAILABILITY STATEMENT}

The datasets presented in this study can be found in online repositories. The names of the repository/repositories and accession number(s) can be found in the article/ Supplementary Material.

\section{ETHICS STATEMENT}

The studies involving human participants were reviewed and approved by the Human Research Ethics Committee of Huazhong University of Science and Technology. The patients/participants provided their written informed consent to participate in this study.

\section{AUTHOR CONTRIBUTIONS}

YS and YL designed the study. YS, JL, JX, JL, TX, JT, LL, and YH carried out data acquisition and analysis. YS, YL, GC, and XZ wrote the manuscript. JX, YH, LL, and JT collected the clinical samples and managed the clinical data. HY and DL contributed to bioinformatics analysis. GC and $\mathrm{XZ}$ were involved in project management and contributed to preparing and making figures and tables. GC and XZ supervised the study. All authors read and approved the final manuscript.

\section{FUNDING}

Our study was supported by the Key Research and Development Plan in China (Grant No. 2017YFB1303100), the National Natural Science Foundation of China (Grant Nos. 82002704, 81927807, 81874090, 81672528, 81773282 \& 81972630), and Individual Innovative Research Funding of Union Hospital (Grant No. 02.03.2019-156).

\section{ACKNOWLEDGMENTS}

We appreciated all involved in this study.

\section{SUPPLEMENTARY MATERIAL}

The Supplementary Material for this article can be found online at: https://www.frontiersin.org/articles/10.3389/fgene.2022.648134/ full\#supplementary-material 


\section{REFERENCES}

Argote Camacho, A. X., González Ramírez, A. R., Pérez Alonso, A. J., Rejón García, J. D., Olivares Urbano, M. A., Torné Poyatos, P., et al. (2021). Metalloproteinases 1 and 3 as Potential Biomarkers in Breast Cancer Development. Ijms 22 (16), 9012. doi:10.3390/ijms22169012

Arthur, M. J. P. (2000). Fibrogenesis II. Metalloproteinases and Their Inhibitors in Liver Fibrosis. Am. J. Physiology-Gastrointestinal Liver PhysiologyGastrointestinal Liver Physiol. 279 (2), G245-G249. doi:10.1152/ ajpgi.2000.279.2.g245

Batra, J., Robinson, J., Soares, A. S., Fields, A. P., Radisky, D. C., and Radisky, E. S. (2012). Matrix Metalloproteinase-10 (MMP-10) Interaction with Tissue Inhibitors of Metalloproteinases TIMP-1 and TIMP-2. J. Biol. Chem. 287 (19), 15935-15946. doi:10.1074/jbc.M112.341156

Beroukhim, R., Brunet, J.-P., Di Napoli, A., Mertz, K. D., Seeley, A., Pires, M. M., et al. (2009). Patterns of Gene Expression and Copy-Number Alterations in Von-Hippel Lindau Disease-Associated and Sporadic clear Cell Carcinoma of the Kidney. Cancer Res. 69 (11), 4674-4681. doi:10.1158/0008-5472.CAN-090146

Brabletz, S., Schuhwerk, H., Brabletz, T., and Stemmler, M. P. (2021). Dynamic EMT: a Multi-tool for Tumor Progression. EMBO J. 40 (18), e108647. doi:10. 15252/embj.2021108647

Bray, F., Ferlay, J., Soerjomataram, I., Siegel, R. L., Torre, L. A., and Jemal, A. (2018). Global Cancer Statistics 2018: GLOBOCAN Estimates of Incidence and Mortality Worldwide for 36 Cancers in 185 Countries. CA: a Cancer J. clinicians 68 (6), 394-424. doi:10.3322/caac.21492

Brew, K., and Nagase, H. (2010). The Tissue Inhibitors of Metalloproteinases (TIMPs): an Ancient Family with Structural and Functional Diversity. Biochim. Biophys. Acta (Bba) - Mol. Cel Res. 1803 (1), 55-71. doi:10.1016/j.bbamcr.2010. 01.003

Cella, D., Grünwald, V., Nathan, P., Doan, J., Dastani, H., Taylor, F., et al. (2016). Quality of Life in Patients with Advanced Renal Cell Carcinoma Given Nivolumab versus Everolimus in CheckMate 025: a Randomised, OpenLabel, Phase 3 Trial. Lancet OncolOncology 17 (7), 994-1003. doi:10.1016/ S1470-2045(16)30125-5

Cheng, G., Fan, X., Hao, M., Wang, J., Zhou, X., and Sun, X. (2016). Higher Levels of TIMP-1 Expression Are Associated with a Poor Prognosis in Triple-Negative Breast Cancer. Mol. Cancer 15 (1), 30. doi:10.1186/s12943-016-0515-5

Cheng, G., Liu, D., Liang, H., Yang, H., Chen, K., and Zhang, X. (2019). A Cluster of Long Non-coding RNAs Exhibit Diagnostic and Prognostic Values in Renal Cell Carcinoma. Aging 11 (21), 9597-9615. doi:10.18632/aging.102407

Cheng, G., Liu, Y., Liu, L., Ruan, H., Cao, Q., Song, Z., et al. (2020). LINC00160 Mediates Sunitinib Resistance in Renal Cell Carcinoma via SAA1 that Is Implicated in STAT3 Activation and Compound Transportation. Aging 12 (17), 17459-17479. doi:10.18632/aging.103755

Cheville, J. C., Lohse, C. M., Zincke, H., Weaver, A. L., and Blute, M. L. (2003). Comparisons of Outcome and Prognostic Features Among Histologic Subtypes of Renal Cell Carcinoma. Am. J. Surg. Pathol. 27 (5), 612-624. doi:10.1097/ 00000478-200305000-00005

Choueiri, T. K., Escudier, B., Powles, T., Mainwaring, P. N., Rini, B. I., Donskov, F., et al. (2015). Cabozantinib versus Everolimus in Advanced Renal-Cell Carcinoma. N. Engl. J. Med. 373 (19), 1814-1823. doi:10.1056/NEJMoa1510016

Cinque, A., Capasso, A., Vago, R., Lee, M. W., Floris, M., and Trevisani, F. (2021). The Role of Circulating Biomarkers in the Oncological Management of Metastatic Renal Cell Carcinoma: Where Do We Stand Now? Biomedicines 10 (1), 90. doi:10.3390/biomedicines 10010090

Cruz-Muñoz, W., Kim, I., and Khokha, R. (2006). TIMP-3 Deficiency in the Host, but Not in the Tumor, Enhances Tumor Growth and Angiogenesis. Oncogene 25 (4), 650-655. doi:10.1038/sj.onc.1209104

Dongre, A., and Weinberg, R. A. (2019). New Insights into the Mechanisms of Epithelial-Mesenchymal Transition and Implications for Cancer. Nat. Rev. Mol. Cel Biol 20 (2), 69-84. doi:10.1038/s41580-018-0080-4

Gong, J., Maia, M. C., Dizman, N., Govindarajan, A., and Pal, S. K. (2016). Metastasis in Renal Cell Carcinoma: Biology and Implications for Therapy. Asian J. Urol. 3 (4), 286-292. doi:10.1016/j.ajur.2016.08.006

Grünwald, B., Harant, V., Schaten, S., Frühschütz, M., Spallek, R., Höchst, B., et al. (2016). Pancreatic Premalignant Lesions Secrete Tissue Inhibitor of
Metalloproteinases-1, Which Activates Hepatic Stellate Cells via CD63 Signaling to Create a Premetastatic Niche in the Liver. Gastroenterology 151 (5), 1011-1024. doi:10.1053/j.gastro.2016.07.043

Grünwald, B., Schoeps, B., and Krüger, A. (2019). Recognizing the Molecular Multifunctionality and Interactome of TIMP-1. Trends Cel Biol. 29 (1), 6-19. doi:10.1016/j.tcb.2018.08.006

Guedez, L., Stetler-Stevenson, W. G., Wolff, L., Wang, J., Fukushima, P., Mansoor, A., et al. (1998). In Vitro suppression of Programmed Cell Death of B Cells by Tissue Inhibitor of Metalloproteinases-1. J. Clin. Invest. 102 (11), 2002-2010. doi: $10.1172 /$ jci2881

Hawthorn, L., Stein, L., Varma, R., Wiseman, S., Loree, T., and Tan, D. (2004). TIMP1 and SERPIN-A Overexpression and TFF3 and CRABP1 Underexpression as Biomarkers for Papillary Thyroid Carcinoma. Head Neck 26 (12), 1069-1083. doi:10.1002/hed.20099

Holten-Andersen, M. N., Murphy, G., Nielsen, H. J., Pedersen, A. N., Christensen, I. J., Høyer-Hansen, G., et al. (1999). Quantitation of TIMP-1 in Plasma of Healthy Blood Donors and Patients with Advanced Cancer. Br. J. Cancer 80 (34), 495-503. doi:10.1038/sj.bjc.6690384

Hsieh, J. J., Purdue, M. P., Signoretti, S., Swanton, C., Albiges, L., Schmidinger, M., et al. (2017). Renal Cell Carcinoma. Nat. Rev. Dis. Primers 3 (1), 2477-2490. doi:10.1038/nrdp.2017.9

Jackson, H. W., Defamie, V., Waterhouse, P., and Khokha, R. (2017). TIMPs: Versatile Extracellular Regulators in Cancer. Nat. Rev. Cancer 17 (1), 38-53. doi:10.1038/nrc.2016.115

Jones, J., Otu, H., Spentzos, D., Kolia, S., Inan, M., Beecken, W. D., et al. (2005). Gene Signatures of Progression and Metastasis in Renal Cell Cancer. Clin. Cancer Res. 11 (16), 5730-5739. doi:10.1158/1078-0432.CCR-04-2225

Jung, K.-K., Liu, X.-W., Chirco, R., Fridman, R., and Kim, H.-R. C. (2006). Identification of CD63 as a Tissue Inhibitor of Metalloproteinase-1 Interacting Cell Surface Protein. EMBO J. 25 (17), 3934-3942. doi:10.1038/ sj.emboj.7601281

Kallakury, B. V., Karikehalli, S., Haholu, A., Sheehan, C. E., Azumi, N., and Ross, J. S. (2001). Increased Expression of Matrix Metalloproteinases 2 and 9 and Tissue Inhibitors of Metalloproteinases 1 and 2 Correlate with Poor Prognostic Variables in Renal Cell Carcinoma. Clin. Cancer Res. 7 (10), 3113-3119. doi:10. $1093 /$ carcin/22.10.1727

Kalluri, R., and Weinberg, R. A. (2009). The Basics of Epithelial-Mesenchymal Transition. J. Clin. Invest. 119 (6), 1420-1428. doi:10.1172/jci39104

Kugler, A., Hemmerlein, B., Thelen, P., Kallerhoff, M., Radzun, H.-J., and Ringert, R.-H. (1998). Expression of Metalloproteinase 2 and 9 and Their Inhibitors in Renal Cell Carcinoma. J. Urol. 160 (5), 1914-1918. doi:10.1097/00005392199811000-00083

LaRocca, G., Aspelund, T., Greve, A. M., Eiriksdottir, G., Acharya, T., Thorgeirsson, G., et al. (2017). Fibrosis as Measured by the Biomarker, Tissue Inhibitor Metalloproteinase-1, Predicts Mortality in Age Gene Environment Susceptibility-Reykjavik (AGES-Reykjavik) Study. Eur. Heart J. 38 (46), 3423-3430. doi:10.1093/eurheartj/ehx510

Leibovich, B. C., Lohse, C. M., Crispen, P. L., Boorjian, S. A., Thompson, R. H., Blute, M. L., et al. (2010). Histological Subtype Is an Independent Predictor of Outcome for Patients with Renal Cell Carcinoma. J. Urol. 183 (4), 1309-1316. doi:10.1016/j.juro.2009.12.035

Li, X., Niu, N., Sun, J., Mou, Y., He, X., and Mei, L. (2020). IL35 Predicts Prognosis in Gastric Cancer and Is Associated with Angiogenesis by Altering TIMP1, PAI1 and IGFBP1. FEBS Open Bio 10, 2687-2701. doi:10.1002/2211-5463. 13005

Liu, Y., Cheng, G., Song, Z., Xu, T., Ruan, H., Cao, Q., et al. (2019). RAC2 Acts as a Prognostic Biomarker and Promotes the Progression of clear Cell Renal Cell Carcinoma. Int. J. Oncol. 55 (3), 645-656. doi:10.3892/ijo.2019.4849

Luo, Y., Shen, D., Chen, L., Wang, G., Liu, X., Qian, K., et al. (2019). Identification of 9 Key Genes and Small Molecule Drugs in clear Cell Renal Cell Carcinoma. Aging 11 (16), 6029-6052. doi:10.18632/aging.102161

Morris, M. R., and Latif, F. (2017). The Epigenetic Landscape of Renal Cancer. Nat. Rev. Nephrol. 13 (1), 47-60. doi:10.1038/nrneph.2016.168

Motzer, R. J., Hutson, T. E., Cella, D., Reeves, J., Hawkins, R., Guo, J., et al. (2013). Pazopanib versus Sunitinib in Metastatic Renal-Cell Carcinoma. N. Engl. J. Med. 369 (8), 722-731. doi:10.1056/NEJMoa1303989

Motzer, R. J., Hutson, T. E., Glen, H., Michaelson, M. D., Molina, A., Eisen, T., et al. (2015). Lenvatinib, Everolimus, and the Combination in Patients with 
Metastatic Renal Cell Carcinoma: a Randomised, Phase 2, Open-Label, Multicentre Trial. Lancet Oncol. 16 (15), 1473-1482. doi:10.1016/S14702045(15)00290-9

Nayim, P., Mbaveng, A. T., Sanjukta, M., Rikesh, J., Kuete, V., and Sudhir, K. (2021). CD24 Gene Inhibition and TIMP-4 Gene Upregulation by Imperata Cylindrica's Root Extract Prevents Metastasis of CaSki Cells via Inhibiting PI3K/Akt/snail Signaling Pathway and Blocking EMT. J. Ethnopharmacology 275, 114111. doi:10.1016/j.jep.2021.114111

Nieto, M. A. (2009). Epithelial-Mesenchymal Transitions in Development and Disease: Old Views and New Perspectives. Int. J. Dev. Biol. 53 (8-10), 1541-1547. doi:10.1387/ijdb.072410mn

Nieto, M. A., Huang, R. Y.-J., Jackson, R. A., and Thiery, J. P. (2016). EMT: 2016. Cell 166 (1), 21-45. doi:10.1016/j.cell.2016.06.028

Özen, Ö., Krebs, B., Hemmerlein, B., Pekrun, A., Kretzschmar, H., and Herms, J. (2004). Expression of Matrix Metalloproteinases and Their Inhibitors in Medulloblastomas and Their Prognostic Relevance. Clin. Cancer Res. 10 (14), 4746-4753. doi:10.1158/1078-0432.ccr-0625-03

Rini, B. I., Escudier, B., Tomczak, P., Kaprin, A., Szczylik, C., Hutson, T. E., et al. (2011). Comparative Effectiveness of Axitinib versus Sorafenib in Advanced Renal Cell Carcinoma (AXIS): a Randomised Phase 3 Trial. The Lancet 378 (9807), 1931-1939. doi:10.1016/S0140-6736(11)61613-9

Seo, D.-W., Li, H., Guedez, L., Wingfield, P. T., Diaz, T., Salloum, R., et al. (2003). TIMP-2 Mediated Inhibition of Angiogenesis. Cell 114 (2), 171-180. doi:10. 1016/s0092-8674(03)00551-8

Song, G., Xu, S., Zhang, H., Wang, Y., Xiao, C., Jiang, T., et al. (2016). TIMP1 Is a Prognostic Marker for the Progression and Metastasis of colon Cancer through FAK-Pi3k/AKT and MAPK Pathway. J. Exp. Clin. Cancer Res. 35 (1), 148. doi:10.1186/s13046-016-0427-7

Tan, Y., Li, X., Tian, Z., Chen, S., Zou, J., Lian, G., et al. (2020). TIMP1 Down-Regulation Enhances Gemcitabine Sensitivity and Reverses Chemoresistance in Pancreatic Cancer. Biochem. Pharmacol. 189, 114085. doi:10.1016/j.bcp.2020.114085

Taube, M. E., Liu, X.-W., Fridman, R., and Kim, H.-R. C. (2006). TIMP-1 Regulation of Cell Cycle in Human Breast Epithelial Cells via Stabilization of p27KIP1 Protein. Oncogene 25 (21), 3041-3048. doi:10.1038/sj.onc.1209336

Thiery, J. P., Acloque, H., Huang, R. Y. J., and Nieto, M. A. (2009). Epithelialmesenchymal Transitions in Development and Disease. Cell 139 (5), 871-890. doi:10.1016/j.cell.2009.11.007

Wan, B., Liu, B., Huang, Y., Yu, G., and Lv, C. (2019a). Prognostic Value of Immune-Related Genes in clear Cell Renal Cell Carcinoma. Aging 11 (23), 11474-11489. doi:10.18632/aging.102548

Wan, B., Liu, B., Yu, G., Huang, Y., and Lv, C. (2019b). Differentially Expressed Autophagy-Related Genes Are Potential Prognostic and Diagnostic Biomarkers in clear-cell Renal Cell Carcinoma. Aging 11 (20), 9025-9042. doi:10.18632/aging.102368

Wang, L., Zhang, C.-g., Jia, Y.-l., and Hu, L. (2020). Tissue Inhibitor of Metalloprotease-1 (TIMP-1) Regulates Adipogenesis of Adipose-Derived
Stem Cells (ASCs) via the Wnt Signaling Pathway in an MMP-independent Manner. Curr. Med. Sci. 40 (5), 989-996. doi:10.1007/s11596-020-2265-2

Wang, Y.-Y., Li, L., Zhao, Z.-S., and Wang, H.-J. (2013). Clinical Utility of Measuring Expression Levels of KAP1, TIMP1 and STC2 in Peripheral Blood of Patients with Gastric Cancer. World J. Surg. Onc 11, 81. doi:10. 1186/1477-7819-11-81

Xu, W.-H., Xu, Y., Wang, J., Wan, F.-N., Wang, H.-K., Cao, D.-L., et al. (2019). Prognostic Value and Immune Infiltration of Novel Signatures in clear Cell Renal Cell Carcinoma Microenvironment. Aging 11 (17), 6999-7020. doi:10. 18632/aging.102233

Yusenko, M. V., Zubakov, D., and Kovacs, G. (2009). Gene Expression Profiling of Chromophobe Renal Cell Carcinomas and Renal Oncocytomas by Affymetrix GeneChip Using Pooled and Individual Tumours. Int. J. Biol. Sci. 5 (6), 517-527. doi:10.7150/ijbs.5.517

Zhang, C., He, H., Hu, X., Liu, A., Huang, D., Xu, Y., et al. (2019). Development and Validation of a Metastasis-Associated Prognostic Signature Based on SingleCell RNA-Seq in clear Cell Renal Cell Carcinoma. Aging 11 (22), 10183-10202. doi:10.18632/aging.102434

Zhou, J., Wang, J., Hong, B., Ma, K., Xie, H., Li, L., et al. (2019). Gene Signatures and Prognostic Values of m6A Regulators in clear Cell Renal Cell Carcinoma - a Retrospective Study Using TCGA Database. Aging 11 (6), 1633-1647. doi:10. 18632/aging.101856

Zurac, S., Neagu, M., Constantin, C., Cioplea, M., Nedelcu, R., Bastian, A., et al. (2016). Variations in the Expression of TIMP1, TIMP2 and TIMP3 in Cutaneous Melanoma with Regression and Their Possible Function as Prognostic Predictors. Oncol. Lett. 11 (5), 3354-3360. doi:10.3892/ol.2016. 4391

Conflict of Interest: The authors declare that the research was conducted in the absence of any commercial or financial relationships that could be construed as a potential conflict of interest.

Publisher's Note: All claims expressed in this article are solely those of the authors and do not necessarily represent those of their affiliated organizations, or those of the publisher, the editors and the reviewers. Any product that may be evaluated in this article, or claim that may be made by its manufacturer, is not guaranteed or endorsed by the publisher.

Copyright (C) 2022 Shou, Liu, Xu, Liu, Xu, Tong, Liu, Hou, Liu, Yang, Cheng and Zhang. This is an open-access article distributed under the terms of the Creative Commons Attribution License (CC BY). The use, distribution or reproduction in other forums is permitted, provided the original author(s) and the copyright owner(s) are credited and that the original publication in this journal is cited, in accordance with accepted academic practice. No use, distribution or reproduction is permitted which does not comply with these terms. 